\title{
Translation Inhibitory Elements from Hox a3 and a11 mRNAs use uORFs for translation inhibition
}

Fatima ALGHOUL, Laure SCHAEFFER, Gilbert ERIANI, Franck MARTIN*

Institut de Biologie Moléculaire et Cellulaire, "Architecture et Réactivité de l'ARN" CNRS UPR9002, Université de Strasbourg, 2 Allée Konrad Roentgen Strasbourg (France)

*Corresponding authors

Email for correspondence: f.martin@ibmc-cnrs.unistra.fr

Running title: TIE a3 and a11 translation inhibition

Keywords: Hox mRNA, Translation Inhibitory Elements, IRES, uORF 


\begin{abstract}
During embryogenesis, Hox mRNA translation is tightly regulated by a sophisticated molecular mechanism that combines two RNA regulons located in their 5'UTR. First, an Internal Ribosome Entry Site (IRES) enables cap-independent translation. The second regulon is a Translation Inhibitory Element or TIE, which ensures concomitant cap-dependent translation inhibition. In this study, we deciphered the molecular mechanisms of Hox a3 and a11 TIE elements. Both TIEs possess an upstream Open Reading Frame (uORF) that is critical to inhibit cap-dependent translation. However, the molecular mechanisms used are different. In TIE a3, we identify a uORF which inhibits cap-dependent translation and we show the requirement of the non-canonical initiation factor eIF2D for this process. The mode of action of TIE a11 is different, it also contains a uORF but it is a minimal uORF formed by an uAUG followed immediately by a stop codon, namely a 'start-stop'. The a11 'start-stop' sequence is located upstream of a highly stable stem loop structure which stalls the $80 \mathrm{~S}$ ribosome and thereby inhibits cap-dependent translation of Hox a11 main ORF.
\end{abstract}




\section{Introduction}

Gene expression constitutes an indispensable cellular process for which the genetic information encodes a functional product, mainly proteins. This process named translation initiates by a cap-dependent mechanism for most cellular mRNAs. It involves a large number of auxiliary proteins termed eukaryotic Initiation Factors (eIFs) which are required for the recruitment of the ribosomes on the mRNA (Hinnebusch, 2014; Merrick and Pavitt, 2018; Pelletier and Sonenberg, 2019; Shirokikh and Preiss, 2018). To ensure fine-tuning of translation, this step is highly regulated. However, several mRNA subclasses are translated by non-canonical mechanisms. For instance, this is the case for homeobox (Hox) mRNAs. Hox genes encode a family of proteins that constitutes transcription factors. Their main function is to orchestrate specific sequential transcription processes during embryonic development. A wealth of experimental data over the last three decades has led to the identification of many cis-regulatory elements that control Hox gene transcriptional patterns, thus giving deeper insights into the expression of Hox mRNAs (Alexander et al., 2009). In fact, the expression of the Drosophila genes Antp and Ubx have been suggested to be under translational control during embryonic development (Oh et al., 1992). More precisely, a subgroup of mRNAs produced from the Antp and Ubx loci contain functional Internal Ribosome Entry Sites (IRES) that allow their translation using a cap-independent mechanism. The IRES activity is modulated during development (Ye et al., 1997). More recently, the presence of other IRES elements in the 5'UTR of subsets of mice HoxA mRNAs (Hoxa3, Hoxa4, Hoxa5, Hoxa9 and Hoxa11) have been demonstrated (Leppek et al., 2020; Xue et al., 2015). Some of these IRESes require the presence of the ribosomal protein RpL38 in the ribosome to efficiently initiate translation, thereby explaining the tissue patterning defective phenotype observed with RpL38 knockout mouse (Kondrashov et al., 2011). The IRES activity in these Hox mRNAs was found to be critical for their appropriate expression. Upon the discovery of the IRES elements in Hox mRNAs, other RNA regulons termed Translational Inhibitory Elements (TIE) were also found in the 5'UTR of Hox mRNAs (Xue et al., 2015). TIEs are located upstream of the previously described IRES. According to the study by Xue et al., these elements efficiently inhibit canonical cap-dependent translation in subsets of HoxA mRNAs (Hoxa3, Hoxa4, Hoxa9 and Hoxa11) by an unknown mechanism (Xue et al., 2015). The action of TIE that ensures efficient blockage of cap-dependent translation, promotes IRESmediated cap-independent translation. TIE and IRES act in synergy to ensure tightly regulated translation during organismal development. Indeed, it has been shown that Hox TIE elements 
ensure that Hox mRNAs are translated solely by their IRES element. Thereby, TIE elements represent the first example of specific RNA elements dedicated to inhibiting specifically capdependent translation in Hox mRNAs. However, the mechanism of action of these elements as well as their structural characterization are still unknown. In this study, we investigate the functional mode of action of TIE elements from a3 and a11 Hox mRNAs that were previously identified and characterized by Xue et al. (Xue et al., 2015). First, we determined their secondary structure by chemical probing assays and then, using cell-free translation extracts and in vivo assays, we deciphered their mode of action. Interestingly, the translation inhibitory mechanism that is mediated by a3 TIE element is radically distinct from the one used by a11. TIE a3 contains a uORF that is translated into a $9 \mathrm{KDa}$ protein through the Hox a3 IRES and that requires the presence of the non-canonical translation initiation factor eIF2D. Indeed, eIF2D has been shown to be involved in diverse functions from translation initiation on specific mRNAs to reinitiation and recycling (Dmitriev et al., 2010; Skabkin et al., 2010; Weisser et al., 2017). On the contrary, TIE a11 contains an UAUG followed by a stop codon and a long stable hairpin. These three elements enable a highly efficient inhibition of cap-dependent translation by TIE a11 that is achieved through a start-stop stalling mechanism of an $80 \mathrm{~S}$ ribosome. 


\section{Materials and Methods}

\section{Plasmids}

For in vitro studies, murine TIE a3 (170 nts) and TIE a11 (216 nts) (sequences were kindly provided by Dr. Maria Barna, they were amplified from mouse E10.5-12.5 cDNA (Xue et al., 2015)) were placed upstream of 5'UTR of human $\beta$-globin (Accession number: KU350152) (50 nts) and Renilla reniformis Luciferase coding sequence (Accession number: M63501) (936 nts). These constructs were cloned in pUC19 vector in the HindIII site then used as a template for further PCR amplifications and site-directed mutagenesis.

For in vivo studies, we introduced an EcoRI restriction site upstream of hRLuc-neo fusion sequence in pmirGLO vector (Promega ${ }^{\circledR}$ ) using Quick Change site-directed mutagenesis kit II XL (Thermo Fischer Scientific ${ }^{\circledR}$ ). Subsequent cloning experiments of TIE a3, TIE a11 and their mutants were performed in pmirGLO vector at EcoRI site using NEBuilder ${ }^{\circledR} H i F i$ DNA Assembly kit. All clones were checked by sequencing.

\section{Cell lines}

Two cell lines were used for our in vivo assays: Human embryonic kidney cell line HEK293FT (ATCC $®$ ) and murine mesenchymal stem cell line C3H10T1/2 (clone 8, ATCC®) CCL26). HEK293FT cells were cultured in Dulbecco's modified Eagle medium (DMEM) with $2 \mathrm{mM}$ of L-Glutamine and 10\% Fetal Bovine Serum (FBS) supplemented with 100 units/ml of Penicillin/Streptomycin. Subcultures were performed after Trypsin-EDTA treatment for dissociation at sub-confluent conditions (70\%-80\%) 1:4 to $1: 10$ seeding at 2$4.10^{4}$ cells $/ \mathrm{cm}^{2}$ according to manufacturer's instructions. C3H10T1/2 cells were cultured in basal DMEM medium supplemented with $2 \mathrm{mM}$ Glutamine, $1.5 \mathrm{~g} / \mathrm{L}$ sodium bicarbonate and 10\% FBS supplemented with $40 \mu \mathrm{g} / \mathrm{ml}$ Gentamicine. Subcultures were performed after Trypsin-EDTA treatment for dissociation at sub-confluent conditions (60\%-70\%). Seeding dilutions were performed at 2000 cells $/ \mathrm{cm}^{2}$ one time per week.

\section{RNA transcription}

Transcription templates were generated by PCR amplification from the plasmids pUC19-TIE. The amplified templates were used for in vitro transcription with recombinant T7 RNA polymerase in the presence of either $\mathrm{m}^{7} \mathrm{G}_{\mathrm{ppp}} \mathrm{G}$ cap analog or non-functional cap analog $A_{p p p} G$ (New England Biolabs ${ }^{\circledR}$ ). To check RNA integrity, an aliquot was mixed with Formamide Dye and loaded on $4 \%$ denaturing polyacrylamide gel. The RNA is visualized under UV light after ethidium bromide staining. To eliminate unincorporated nucleotides, the RNA sample was loaded on a gel filtration Sephadex G25-column (Pharmacia Fine Chemicals), proteins 
are then eliminated by phenol extraction and the RNA transcripts are precipitated with $0.25 \mathrm{M}$ $\mathrm{NaCl}$ in ethanol. After centrifugation, RNA pellets were dried and resuspended in autoclaved milli-Q water. The concentration of purified RNA samples was determined by absorbance measurement at $260 \mathrm{~nm}$.

\section{In vitro translation assays in cell-free translation extracts}

In vitro translation was carried out using increasing concentrations of mRNA transcripts with self-made untreated Rabbit Reticulocyte Lysate (RRL), amino acid mixture containing all the amino-acids except methionine (1 mM of each), RNasin (Promega $\left.{ }^{\circledR}\right), 75 \mathrm{mM} \mathrm{KCl}, 0.5 \mathrm{mM}$ $\mathrm{MgCl}_{2}, 3.8 \mathrm{mCi}\left[{ }^{35} \mathrm{~S}\right]$ methionine and autoclaved milli-Q water. Reaction mixture was incubated at $30^{\circ} \mathrm{C}$ for $1 \mathrm{hr}$. Aliquots of translation mixture were analysed by SDS PAGE $(10 \%)$ (Laemmli, 1970) and translation products were visualized by phosphor-imaging. In vitro translation assays with wheat germ extract (Promega ${ }^{\circledR}$ ) were performed according to manufacturer's instructions. In vitro translation assays with HeLa cell extract and drosophila S2 cell extract were performed as previously described (Thoma et al., 2004; Wakiyama et al., 2006).

\section{Chemical probing}

\section{- Probing with DMS}

Modification by Dimethyl Sulfate (DMS) was performed on 2 pmoles of each RNA (TIE a3 and TIE a11). The RNA is first incubated for $15 \mathrm{~min}$ in dimethylsufate (DMS) buffer (50 $\mathrm{mM}$ Na Cacodylate ( $\mathrm{pH} 7.5), 5 \mathrm{mM} \mathrm{MgCl}_{2}$ and $100 \mathrm{mM} \mathrm{KCl}$ ) and $1 \mu \mathrm{g}$ of yeast total tRNA (Sigma- Aldrich ${ }^{\circledR}$ ) and then modified with 1.25\% DMS reagent (diluted with ethanol 100\%) with $10 \mathrm{~min}$ incubation at $20^{\circ} \mathrm{C}$ and stopped on ice. Modified transcripts are precipitated with $0.25 \mathrm{M} \mathrm{NaCl}, 0.1 \mathrm{mg} / \mathrm{ml}$ glycogen in ethanol. RNA pellets were dried and resuspended in autoclaved milli-Q water. Modified nucleotides were detected by primer extension arrests that were quantified. The intensity of the RT stops is proportional to the reactivity for each nucleotide.

\section{- Probing with CMCT}

Similarly, modification by 1-cyclohexyl-3-(2-morpholinoethyl) carbodiimide metho-ptoluene sulfonate (CMCT) was performed on 2 pmoles of each RNA (TIE a3 and TIE a11). Each RNA is incubated for $20 \mathrm{~min}$ in CMCT buffer $(50 \mathrm{mM} \mathrm{Na}$ borate $(\mathrm{pH} 8.5) ; 5 \mathrm{mM}$ $\left.\mathrm{MgCl}_{2} ; 100 \mathrm{mM} \mathrm{KCl}\right)$ and $1 \mu \mathrm{g}$ of yeast total tRNA. Then modifications were performed with $10.5 \mathrm{~g} / \mathrm{L}$ CMCT reagent with $20 \mathrm{~min}$ incubation at $20^{\circ} \mathrm{C}$ and stopped on ice. Modified transcripts are precipitated with $0.25 \mathrm{M} \mathrm{NaCl}, 0.1 \mathrm{mg} / \mathrm{ml}$ glycogen in ethanol. RNA Pellets were dried and resuspended in autoclaved milli-Q water. Modified nucleotides were detected 
by primer extension arrests that were quantified. The intensity of the RT arrests is proportional to the reactivity for each nucleotide.

\section{Primer extension}

Reverse transcription was carried out in a $20 \mu$ l-reaction with 2 pmoles of RNA and 0.9 pmoles of 5' fluorescently labelled primers. We used fluorescent Vic and Ned primers (Thermo Fischer Scientific) of same sequence for all reverse transcription reactions which are complementary to the $\beta$-globin 5'UTR from nucleotides 6-37 :

5'-GGTTGCTAGTGAACACAGTTGTGTCAGAAGC-3'. First, the RNA was unfolded by a denaturation step at $95^{\circ} \mathrm{C}$ for $2 \mathrm{~min}$. Then, fluorescent primers are annealed for $2 \mathrm{~min}$ at $65^{\circ} \mathrm{C}$ followed by incubation on ice for $2 \mathrm{~min}$. Samples are incubated in a buffer containing $83 \mathrm{mM}$ $\mathrm{KCl}, 56 \mathrm{mM}$ Tris- $\mathrm{HCl}$ (pH 8.3), $0.56 \mathrm{mM}$ each of the four deoxynucleotides (dNTP), $5.6 \mathrm{mM}$ DTT and $3 \mathrm{mM} \mathrm{MgCl}_{2}$. Reverse transcription was performed with 1 unit of Avian Myoblastosis Virus (AMV) reverse transcriptase (Promega ${ }^{\circledR}$ ) at $42^{\circ} \mathrm{C}$ for $2 \mathrm{~min}, 50^{\circ} \mathrm{C}$ for 30 min and finally $65^{\circ} \mathrm{C}$ for $5 \mathrm{~min}$. In parallel, sequencing reactions were performed in similar conditions, but supplemented with $0.5 \mathrm{mM}$ dideoxythymidine or or dideoxycitidine triphosphate (ddTTP or ddCTP) (protocol adapted from (Gross et al., 2017)). The synthesized cDNA were phenol-chloroform extracted and precipitated. After centrifugation, the cDNA pellets were washed, dried and resuspended in $10 \mu$ deionized Hi-Di formamide (freshly prepared highly deionized formamide). Samples were loaded on a 96-well plate for sequencing on an Applied Biosystems 3130xl genetic analyzer. The resulting electropherograms were analyzed using QuSHAPE software (Karabiber et al., 2013), which aligns signal within and across capillaries, as well as to the dideoxy references of nucleotide at specific position and corrects for signal decay. Normalized reactivities range from 0 to 2 , with 1.0-2.0 being the range of highly reactive positions. A preliminary secondary structure model was first initiated by mfold (Mathews et al., 2016) and then edited according to reactivity values.

\section{Sucrose gradient analysis}

To analyse the assembly of ribosomal preinitiation complexes on the RNA of interest, the complexes were loaded on $7-47 \%$ sucrose gradients containing $5 \mathrm{mM} \mathrm{MgCl} 2,25 \mathrm{mM}$ Tris$\mathrm{HCl}$ (pH 7.5), $1 \mathrm{mM}$ DTT and $50 \mathrm{mM} \mathrm{KCl}$. We used the specific translation inhibitors GMPPNP (4 mM), cycloheximide $(1 \mathrm{mg} / \mathrm{mL})$, geneticin $(0.7 \mathrm{mM})$, hygromycin $(0.5 \mathrm{mg} / \mathrm{mL})$ and edeine $(10 \mathrm{mM})$, they were added to the RRL with a mix containing the 20 amino acids at 1.5 $\mathrm{mM}$ each, RNasin (Promega ${ }^{\circledR}$ ), $35 \mathrm{mM} \mathrm{KCl}$ and $0.24 \mathrm{mM}$ or $2.4 \mathrm{mM} \mathrm{MgCl}_{2}$, prior to incubation with the 5 ' capped radioactive mRNA of interest. The assembled pre-initiation 
complexes were formed by incubation in $\mathrm{RRL}$ at $30^{\circ} \mathrm{C}$ for $5 \mathrm{~min}$. Then, $8 \mathrm{mM} \mathrm{MgAc}_{2}$ was added and one volume of 7\% sucrose. Samples were then layered on the surface of 11-mL 7$47 \%$ sucrose gradient and centrifuged for $2 \mathrm{~h} 30$ in an SW41 rotor at $37,000 \mathrm{rpm}$ at $4^{\circ} \mathrm{C}$. After centrifugation, the whole gradient is fractionated, and the mRNA is localized by measuring radioactivity in each collected fraction by Cerenkov counting in a scintillation counter.

\section{Mass spectrometry and data processing}

Protein extracts were digested with sequencing-grade trypsin (Promega ${ }^{\circledR}$ ) as previously described (Chicher et al., 2015; Prongidi-Fix et al., 2013). Peptide digests were analysed by nano LC-MS/MS and MS data were searched by the Mascot algorithm against the UniProtKB database from Oryctolagus cuniculus (rabbit). Identifications were validated with a protein False Discovery Rate (FDR) of less than 1\% using a decoy database strategy. The total number of MS/MS fragmentation spectra was used to quantify each protein from three independent biological replicates. This spectral count was submitted to a negative-binomial test using an edge R GLM regression through the R-package. For each identified protein, an adjusted P-value corrected by Benjamini-Hochberg was calculated, as well as a protein foldchange ( $\mathrm{FC}$ is the ratio of the average of spectral counts from a specific complex divided by the average of spectral counts from a reference protein complex). The results are presented in a volcano plot using protein $\log 2 \mathrm{FC}$ and their corresponding adjusted $\log _{10} \mathrm{P}$-values. The proteins that are up-regulated in each condition are shown in red (TIE a3 versus $\beta$-globin mRNA, TIE a1 1 versus $\beta$-globin mRNA and TIE a3 versus TIE a11).

\section{In vivo luciferase assay}

For in vivo luciferase assay, HEK293T cells and C3H10T1/2 cells were transfected in 6-well plates with various constructs of pmirGlo vector (Promega ${ }^{\circledR}$ ). Transfection was performed using Turbofect transfection reagent (Thermo Fischer scientific $®$ ) according to manufacturer's instructions. Cells were collected $24 \mathrm{hrs}$ post-transfection. Luciferase assay was performed using Dual-Glo luciferase kit (Promega ${ }^{\circledR}$ ) according to manufacturer's instructions. Firefly Luciferase activities were measured to monitor transfection efficiency in order to normalize Renilla luciferase activities for each construct.

\section{Co-transfection assay of siRNAs and reporter plasmid in HEK293T cells.}

HEK293FT cells were used to test the effect of inhibition of eIF2D knock-down, eIF4E knock down and a non-target siRNA pool as a negative control on Renilla luciferase expression (hRluc-neo) in pmirGLO vectors. We used ON-TARGETplus human siRNAs against eIF2D (catalog number L-003680-01-00), siRNA against eIF4E (catalog number J-003884-10-00) and non-target pool of siRNAs (catalog number D-001810-10-05) purchased from Horizon 
Discovery. HEK293T cells were cultured according to manufacturer's instructions (ATCC®) for $24 \mathrm{hr}$ and used for co-transfection by siRNAs and reporter plasmid. We used $2 \times 10^{5}$ cells in $1 \mathrm{ml}$ of culture medium without antibiotics. Upon reaching $70 \%$ confluence, cells were transfected by 5 pmoles of siRNAs in different wells with $500 \mathrm{ng}$ of reporter plasmid. Transfections were performed with Lipofectamine 2000 (Invitrogen $®$ ) according to manufacturer's instructions. After $48 \mathrm{~h}$, cells were washed twice by phosphate buffered saline (PBS1X) and incubated with Passive Lysis Buffer (PLB) 1X for 15 min. Luciferase assay was performed according to manufacturer's instructions. Protein concentration was measured by Bradford's assay. The impact of silencing on TIE-mediated translation inhibition was measured by luciferase assay according to manufacturer's instructions as previously mentioned.

\section{Western Blot against eIF2D, eIF4E and GAPDH}

The silencing efficiency was quantified by western blots using rabbit polyclonal anti-eIF2D antibody (12840-1-AP) from Proteintech, mouse monoclonal anti- eIF4E antibody (sc-9976) and mouse polyclonal anti-GAPDH antibody (sc-1377179) from Santa Cruz Biotechnology. For that, $20 \mu \mathrm{g}$ of protein extracts were loaded on 10\% polyacrylamide SDS PAGE. After migration, proteins were transferred to an Immobilin-P membrane (Millipore ${ }^{\circledR}$ ) at 10 Volts for $1 \mathrm{~h}$ in a semi-dry apparatus (Trans-Blot ${ }^{\circledR} \mathrm{SD}$ ) on a PVDF membrane (PolyVinyliDene Fluoride) that had been previously activated with 100\% methanol for few seconds and a transfer buffer pH 8 (25 mM Tris; $200 \mathrm{mM}$ glycine; 20\% ethanol). After transfer, the membrane was saturated for $2 \mathrm{~h}$ by blocking buffer ( $5 \%$ milk, $0.05 \%$ Tween-20, PBS 1X). Primary antibodies were added at dilutions recommended by the manufacturers in blocking buffer, the membranes were incubated overnight at $4^{\circ} \mathrm{C}$. Then, the membranes were washed three times by PBST (PBS 1X; 0.05\% Tween-20) to remove the excess of primary antibodies. Then, membranes were incubated with secondary HRP-conjugated antibody for $1 \mathrm{~h}$ at room temperature followed by three washing steps. The signal produced by reaction between HRP and ECL (Kit ECL Plus Western Blotting Detection System, GE Healthcare ${ }^{\circledR}$ ) was detected by chemiluminescence using imaging Chemidoc (Biorad $\mathbb{R})$.

\section{Ribosome toe printing assay}

Toe printing assay was adapted from previously established protocols (Martin et al., 2011, 2016). Briefly, RRL were incubated for $5 \mathrm{~min}$ at $30^{\circ} \mathrm{C}$ then $10 \mathrm{~min}$ on ice with buffer containing $1 \mathrm{U} / \mu \mathrm{l}$ of recombinant $\mathrm{RNasin}$ (Promega ${ }^{\circledR}$ ), $75 \mathrm{mM} \mathrm{KCl} 0.5 \mathrm{mM} \mathrm{MgCl}$, and 1.3 $\mathrm{mM}$ of puromycin prior to initiation complex assembly. Then, the pre-initiation complexes are formed by incubation with $500 \mathrm{nM}$ of the RNA of interest in the presence of specific 
inhibitors such as cycloheximide $(1 \mathrm{mg} / \mathrm{ml})$ or GMP-PNP $(4 \mathrm{mM})$ for $5 \mathrm{~min}$ at $30^{\circ} \mathrm{C}$ and then 20 min on ice. Then, the pre-initiation complexes were complemented with one volume of ice-cold buffer A containing $20 \mathrm{mM}$ Tris- $\mathrm{HCl}$ (pH 7.5), $100 \mathrm{mM} \mathrm{KAc}, 2.5 \mathrm{mM} \mathrm{MgAc} 2,2 \mathrm{mM}$ DTT, $1 \mathrm{mM}$ ATP and $0.25 \mathrm{mM}$ spermidine and placed on ice. In order to separate ribosomal complexes from the non-ribosomal fraction, samples were centrifuged at 88,000 rpm in S100AT3 rotor (Sorvall-Hitachi) at $4^{\circ} \mathrm{C}$ for $1 \mathrm{~h}$. After centrifugation, the pellets containing the pre-initiation complexes were resuspended in $30 \mu \mathrm{l}$ of ice-cold buffer A and incubated with 5, radioactively labelled DNA oligonucleotide complementary to nts 22-51 of renilla luciferase coding sequence for $3 \mathrm{~min}$ at $30^{\circ} \mathrm{C}$. Then, $1 \mu \mathrm{l}$ of a $320 \mathrm{mM} \mathrm{Mg}(\mathrm{Ac})_{2}, 4 \mu \mathrm{l}$ of a dNTP mixture (containing $5 \mathrm{mM}$ of dATP, dGTP, dTTP and dCTP), 10 units of recombinant RNAsin (Promega ${ }^{\circledR}$ ) and 1 unit/ $\mu$ Avian Myoblastosis virus reverse transcriptase (Promega ${ }^{\circledR}$ ) were added and incubated for $1 \mathrm{~h}$ at $30^{\circ} \mathrm{C}$. The synthesized cDNAs were analysed on $8 \%$ PAGE next to sequencing ladders. 


\section{Results}

\section{TIE-mediated inhibition recapitulated in RRL}

To dissect the mechanism of TIE-mediated inhibition, we first set-up an efficient cell-free assay. We used RRL and performed in vitro experiments using several reporter constructs. To analyse their translation efficiency, capped mRNAs were translated in RRL in the presence of $\left[{ }^{35} \mathrm{~S}\right]$-methionine to verify the size of the expected synthesized protein and luciferase activity was measured to determine their translation efficiency. In order to standardize the measured translation activities, we inserted the TIE elements identified and characterized by Xue et al. (Xue et al., 2015), in murine Hox a3 and a11 mRNAs upstream of the well-characterized human $\beta$-globin 5'UTR (Fig. 1A). The human $\beta$-globin allows translation strictly by a capdependent mechanism (Fletcher et al., 1990). Therefore, in order to evaluate the inhibition due to TIEs, we used a reporter mRNA containing the sole human $\beta$-globin 5'UTR as a reference. First, we performed translation experiments with increasing amounts of mRNA and determined that with concentrations higher than $100 \mathrm{nM}$, the translation yield reached a plateau (Fig. S1A). In order to avoid any titration effect due to excess of mRNA, we performed all translation assays at an mRNA concentration of $50 \mathrm{nM}$, which enables subsaturating conditions. TIE a3 and a11 efficiently promote a translation inhibition by $79 \%$ and 91\% respectively (Fig. 1A). Therefore, our cell-free translation assay using RRL efficiently recapitulates the previously described TIE-mediated translation inhibition (Xue et al., 2015). Likewise, TIE-mediated inhibition was efficiently recapitulated in other cell-free translation systems from other organisms like Wheat Germ Extracts, drosophila S2 cell extracts and human HeLa cell extracts (Fig. S1B). Moreover, the same constructs were introduced in a plasmid that allowed us to monitor translation inhibition in vivo. We tested two cell lines that have been shown to express Hox genes, namely human HEK293T and murine mesenchymal stem cell line C3H10T1/2 (Phinney et al., 2005). In these cells, translation inhibition by TIE a3 and a11 is $98 \%$ and $88 \%$ respectively (Fig. S1C). Next, to define the minimal active domains of a3 and a11, sequential 5' deletions were performed. In each experiment, translation for each construct was compared to the control (w/o TIE) (Fig. 1B). First, we tested large deletions in order to roughly determine the functional domain (Fig. S1D), then more precise deletions to map exactly the 5' end of functional domains for a3 and a11 (Fig. 1B). Deletion of $68 \mathrm{nts}$ in TIE a3 does not affect inhibition (81\%). A further deletion of 113 nts completely abolishes the translation inhibition of TIE a3 (10\%). Therefore, the minimal a3 element encompasses nucleotides 68 to 170 . Concerning TIE a11, the situation is not as clear. 
In fact, the inhibition is only partially reduced (70\%) when $153 \mathrm{nts}$ are deleted and completely lost when $161 \mathrm{nts}$ are deleted. In this case, the deletions indicate that elements essential for translation inhibition are most likely located between residues 139 to 216 . In conclusion, these experiments allowed the localisation of essential RNA elements required for a3 and a1 1 RNA regulons that are required to retain their full inhibitory function.

\section{TIE elements have distinct secondary structures}

To gain further insights into the structural and functional properties of TIE elements, we performed chemical probing using DMS and CMCT reagents for both TIE a3 and TIE a11 (Fig. 2). Since modifications were performed in triplicates, the average of reactivity was calculated for each nucleotide at a specific position (Fig. S2). With this reactivity, we built a secondary structural model for both TIE a3 and a11. TIE a3 contains a 5' proximal stem-loop and another bigger structure comprising two-way junctions (Fig. 2A). For TIE a11, the higher GC content (64\%) than TIE a3 (45\%) suggests more stable structure. Our probing experiments confirmed this statement. It comprises four stem-loops and a three-way junction structure (Fig. 2B). To further validate our models, the secondary structures of both TIEs were also probed in the frame of the full-length Hox 5'UTR which contains the IRES element downstream of the TIE. The reactivities for each nucleotide obtained with isolated TIEs and with TIEs embedded in full-length 5'UTR were highly similar suggesting that the TIEs do fold independently from the IRES (Fig. S2). Using these two models, we wanted to further characterize the structure-function relationships of both TIE elements.

\section{TIE a3 contains an upstream ORF that inhibits translation}

The 5' truncations experiments allowed us to pinpoint critical elements required for translation inhibition. Interestingly, the minimal a3 contains putative uORFs starting from two putative uAUGs at positions 111-113 and 123-125 respectively (Fig. 3A). In order to test their implication in the translation inhibition, both uAUGs were mutated independently into UAC thereby eliminating any possibility of AUG-like codon recognition. Interestingly, the mutation of AUG111 completely abolishes the inhibition by TIE a3 thereby confirming its implication. On the contrary, this is not the case for AUG123 (Fig. 3A). This is in good agreement with the fact that AUG111 has an optimal Kozak sequence (A at -3 and G at +4 ), thereby the ribosome initially recognizes it during scanning along the 5'UTR (Kozak, 1986). To further confirm the assembly of the ribosome on uAUG111, we mutated it into AUG-like codons. We tested previously described AUG-like codons such as AUU, CUG, GUG and ACG. None of the tested AUG-likes are used for translation inhibition indicating that TIE a3 requires a genuine AUG start codon (Fig. S3A). Since the AUG111 is involved in a stem, it is 
possible that the absence of inhibition with the AUG-likes is actually due to the disruption of the stem. To rule out this possibility, we mutated the AUG into CUG and GUG and inserted simultaneously the compensatory mutations that enable the formation of the stem with the mutated CUG and GUG codons. In both mutants, the inhibition was fully destroyed indicating that efficient inhibition requires a genuine AUG start codon independently of the secondary structure (Fig. S3A). Next, we confirmed the use of uAUG111 by toe printing assay. As expected, a canonical +16 reverse transcription arrest from uAUG111 was clearly detected with GMP-PNP and less efficiently with cycloheximide. Accordingly, when the uAUG is mutated to UAC, the +16 toe-print disappears (Fig. 3B). Altogether, this data confirm that a pre-initiation complex efficiently assembles on the uAUG111. We then wondered whether the ribosome assembled on this AUG codon proceeds to translation elongation resulting in a polypeptide synthesis encoded by the uORF. By performing sucrose gradient analysis, we detected polysome formation suggesting that efficient translation is occurring from uAUG111 (Fig. S3B). Accordingly, mutation of uAUG111 drastically reduces the amount of polysomes and the formation of $48 \mathrm{~S}$ complexes in the presence of GMP-PNP thereby corroborating that the translation is starting on uAUG111 (Fig. S3B). In Hox a3 5'UTR, the uORF starting from uAUG111 is extending through the full IRES. To check further whether the uORF is indeed translated through the full length Hox a3 5'UTR, we first deleted a single nucleotide (G333) to change the frame and thereby producing a fusion protein formed by the peptide produced from the uORF and Renilla Luciferase. Indeed, with this single frameshifting point mutation, we could detect a longer protein demonstrating that the pre-initiation complex assembled on the uAUG111 indeed proceeds to translation elongation and is efficiently translating through the full length 5'UTR of Hox a3 mRNA (Fig. 4A). We also verified the translation from uAUG111 with our reporter constructs containing only the TIE a3 element. Likewise, the insertion of a single frameshifting nucleotide (A220) allows the detection of a longer fusion protein (Fig. S4A). Remarkably, with a double mutant that combines the mutation of the uAUG111 to ACG with the (A220) insertion, a mixture of two proteins is detected, the fusion protein and the more abundant Renilla Luciferase protein. Indeed, this confirms that the ribosome requires the uAUG111 but still able to recognize, although less efficiently, the AUG-like ACG as a start codon (Fig. S4A). Similarily, when we use the native full-length hox a3 mRNA, we detect the Hox a3 uORF protein of 9 KDa size (Fig. S4B). Altogether, our cell-free translation assays demonstrate that Hox TIE a3 translation is achieved by translation of a uORF that starts at AUG111 codon that extends through the whole Hox a3 5'UTR. To confirm these results in vivo, we generated reporter constructs in the plasmid pmirGlo that 
contains TIE elements upstream of Renilla luciferase (hRluc). Values were normalized to that of control enhanced Firefly luciferase (luc2) to calculate the luciferase activity for each report (Fig. 4B). As expected, wild type TIE a3 blocks translation very efficiently in both HEK293T and $\mathrm{C} 3 \mathrm{H} 10 \mathrm{~T} 1 / 2$ cells. When the uAUG111 is mutated to UAC, the inhibition is significantly affected in both HEK293T and C3H10T1/2 cells at respectively 57\% and 45\% compared to wild type TIE a3 (Fig. 4B). Although the inhibition is not fully abolished, these experiments confirmed that the codon AUG111 is critical for efficient translation inhibition in Hox a3 in vivo.

\section{TIE a11-mediated inhibition is mediated by a stalled $80 \mathrm{~S}$ ribosome}

We next asked whether TIE a11 has a similar inhibitory mechanism. Deletion experiments suggested that critical elements were located in the region 139 to 216 . We also found that TIE a11 contains two putative upstream AUGs at positions 84-86 and 159-161. Mutations of both AUG84 and AUG159 had no impact on translation inhibition (Fig. 5A). According to our 2D model, a long GC-rich stable stem loop (SL) structure $(\Delta \mathrm{G}=-25.00 \mathrm{kcal} / \mathrm{mol})$ spans nucleotides 104-154 (Fig. 2B). This long hairpin comprises sixteen G-C base pairs that can putatively interfere with the progression of a pre-initiation scanning complex. To test the inhibitory efficiency of this stem-loop, we transplanted it in a strictly cap-dependent reporter mRNA containing the 5'UTR of $\beta$-globin upstream of the luciferase coding sequence. The a11 SL was inserted in the middle of the 5'UTR, in this construct the first 25 nucleotides from the 5 ' proximity are unfolded thereby ensuring proper access to the 5' cap. Interestingly, the translation of this mRNA was significantly abolished showing that this stem loop on its own is sufficient to inhibit cap-dependent translation when transplanted in another mRNA (Fig. S5). Strikingly, in TIE a11, uAUG84 codon is located 19 nts upstream of the inhibiting SL. This distance is compatible with the assembly of a pre-initiation complex on uAUG84 without clashing with the SL. Moreover, the distance between the uAUG and the SL is optimal for favouring AUG recognition by scanning arrest of the pre-initiation complex forced by the SL. Importantly, the uAUG84 is immediately followed by a stop codon UAG87. The sequence context of the uAUG84 (A at -3 and $U$ at +4 ) is suboptimal compared to the consensus Kozak sequence. This unique combination of start-stop codon upstream of stem loop structure raised the question of whether the ribosome is forced to recognize this $\mathrm{uAUG}$ despite a suboptimal Kozak context. To address this hypothesis, we mutated the stop codon UAG87 to UGG thereby creating a uORF. When the stop is mutated, a small peptide is produced from the translation of uAUG84 through 5'UTR, which we called a11 uORF (Fig. 5B). This experiment demonstrates that uAUG84 is indeed efficiently used as a start codon 
despite its sub-optimal sequence context. Unfortunately, the presence of the highly stable SL is not compatible with the toe-printing assay. Indeed, premature RT arrests occur due to the presence of the highly stable SL, rendering the toe-printing assay on TIE a11 impossible. Therefore, to further confirm that the ribosome is efficiently assembled on uAUG84, we performed sucrose gradient analysis with radiolabelled mRNAs. With wild type TIE a11, an $80 \mathrm{~S}$ complex efficiently accumulates in the presence of cycloheximide as expected. However, an $80 \mathrm{~S}$ complex is also detected without inhibitor indicating that the $80 \mathrm{~S}$ complex is in fact a stalled ribosome (Fig. 5C). The mutation of uAUG84 to UAC drastically reduces the amount of $80 \mathrm{~S}$ complex; in contrast, mutation of uAUG159 to UAC does not affect $80 \mathrm{~S}$ accumulation. This further confirms that the stalled $80 \mathrm{~S}$ complex is indeed assembled on the uAUG84. Altogether, this data show that a stalled ribosome is indeed assembled on uAUG84 and the stalling is caused by the synergistic effect of a stop codon next to the AUG and a stable SL downstream of the start-stop of a11.

\section{Mass spectrometry analysis pre-initiation complexes programmed by TIE a3 and a11}

To further characterize the two different modes of action employed by a3 and a11, we identified the factors specifically acting in such mechanisms. For that, we purified preinitiation complexes programmed by TIE a3 and a11 suitable for Mass Spectrometry analysis. Briefly, ribosomes were assembled on chimeric biotinylated mRNA-DNA molecules and immobilized on streptavidin-coated beads after incubation with RRL in the presence of cycloheximide or GMP-PNP. Complexes were then eluted by DNase treatment as previously described (Chicher et al., 2015; Prongidi-Fix et al., 2013) and analysed by Mass Spectrometry. Three different mRNA constructs were used, TIE a3 upstream of 5'UTR $\beta$ globin, TIE a11 upstream of 5'UTR $\beta$-globin, and 5'UTR $\beta$-globin as a negative control. Comparison between the three mRNAs blocked with cycloheximide enabled the identification of specific factors interacting with each RNA (Fig. 6). Interestingly, for TIE a3, we identified a set of translation-related proteins. Among the strongest hits, we found eIF2D, a noncanonical GTP-independent initiation factor which has been shown to be involved in the initiation step on specific mRNAs (Dmitriev et al., 2010; Vaidya et al., 2017; Vasudevan et al., 2020), reinitiation on main ORF (Ahmed et al., 2018; Weisser et al., 2017) and recycling after translation termination (Skabkin et al., 2010, 2013; Young et al., 2018). Another interesting hit is methionine aminopeptidase MetAP1 which removes N-terminal methionine from nascent proteins in a co-translational manner (Varland et al., 2015). Other factors that are linked to translation have been selected such as the scanning factor eIF1A and its isoform eIF1A-X, eIF3a, Arginyl- and Leucyl-tRNA synthetases QARS and LARS, DEAD-box 
helicases DHX36 and DDX39B, elongation factor HBS1L and RpL38 ribosomal protein. For TIE a11, we identified different translation-related proteins among which are ASAP1, a GTPase activator protein, MetAP1, RpL38, Valyl-tRNA synthetase and eIF3j, another subunit of initiation factor eIF3 usually dissociating at early stages of initiation to allow mRNA entry (Aylett et al., 2015; Young and Guydosh, 2019) thereby, unlikely to be present in initiation complexes. When comparing TIE a3 with TIE a11, we could detect some initiation factors and translation-related proteins specific for a3 like eIF2D, eIF1A, eIF1A-X, eIF5B, LARS, QARS, DHX21 and HBS1L (Fig. 6). These results show a variation in the translation factors involved which hints two distinct TIE-mediated inhibitions. Similarly, we purified programmed pre-initiation complexes blocked by GMP-PNP (Fig. S6). By comparing a3 to either $\beta$-globin or a11 mRNAs, we found again an enrichment of eIF2D as a3-specific factor. Interestingly, we also found an enrichment of PKR protein (also called eIF2AK2) for both a3 and a11 (Fig. S6). PKR is known to bind double-stranded RNA during viral infection which mediates its auto-activation and induces the phosphorylation of eIF2 $\alpha$ subunit (Adomavicius et al., 2019). This leads to the inhibition of mRNA translation. The enrichment of both eIF2D and PKR for a3 raised the question of whether eIF2D is indeed mediating the translation of a $3 \mathrm{uORF}$ by an alternative mechanism. To address this hypothesis and the involvement of eIF2D, we conducted a set of in vivo experiments.

\section{Translation inhibition by TIE a3 requires eIF2D}

After specifically identifying eIF2D by Mass Spectrometry analysis for TIE a3-ribosomal complex, we were interested in getting more insights into how this factor might be involved. Previous studies have shown that eIF2D is a non-canonical translation initiation factor which delivers tRNA to the P-site of the ribosome in a GTP-independent manner (Dmitriev et al., 2010). It has been shown to be involved in the initiation step on specific mRNAs (Dmitriev et al., 2010; Vaidya et al., 2017; Vasudevan et al., 2020), reinitiation on main ORF (Ahmed et al., 2018; Weisser et al., 2017). Additionally, other studies showed that eIF2D is required for recycling after translation termination (Skabkin et al., 2010, 2013; Young et al., 2018). To confirm the involvement of eIF2D in TIE a3-mediated inhibition mechanism, we performed a co-transfection assay in HEK293T cell line using siRNA against either eIF2D, eIF4E or nontarget pool of siRNAs together with a reporter plasmid harbouring TIE a3. As a control, we used reporter plasmids with TIE a11 and the same construct without TIE. After 48 hours incubation, cells were lysed for western blot analysis and luciferase assay (Fig. 7A). Luciferase values were normalized to the reporter without TIE. We have previously shown that a3 and a11-mediated translation inhibition is achieved through cap-dependent translation 
of TIE uORFs. As expected, silencing of eIF4E (at efficiency of $74 \%$ and $76 \%$ respectively), which will significantly affect cap-dependent translation, drastically impairs a3- and a11mediated translation inhibition. Interestingly, silencing eIF2D at an efficiency of $76 \%$, also drastically abolishes a3-mediated inhibition and luciferase expression is restored to $85 \%$ (Fig. 7A). On the contrary, the silencing of eIF2D at efficiency of $81 \%$ has no significant effect on a11-mediated inhibition. Altogether, this confirms the requirement of eIF2D for efficient a3 inhibition but not for a11. This conclusion is in good agreement with our previous Mass Spectrometry analysis of a3-ribosomal complexes blocked by translation inhibitors, which show the specific presence of eIF2D in the initiation complexes programmed with TIE-a3 (Fig. 6 \& S6). The fact that we found eIF2D in pre-initiation complexes suggests that eIF2D is involved in the initiation of a $3 \mathrm{uORF}$. Since a $3 \mathrm{uORF}$ is long and extends downstream the AUG start codon of the main CDS in native Hoxa3 mRNA, which means that the a3 uORF partially overlaps the main CDS, a mechanism using a reinitiation event after a3 uORF translation is impossible. Therefore, we rather favour a model in which eIF2D is required for a3 initiation. Previous studies have shown that an A-motif upstream of an uAUG has been shown to be important for proper eIF2D recruitment (Dmitriev et al., 2010). Interestingly, a closer look at the sequences in the TIE a3 uORF revealed A-rich motifs upstream and downstream of uAUG111. We tested the implication of both A-motifs, AAAA107 upstream of the AUG and AAAAA147 downstream of the AUG, in TIE-a3 mediated inhibition (Fig. 7B). In order to avoid any side effect due to mutation in the sequence context around the uAUG, we kept an optimal Kozak sequence and mutated the As at position 107-110 to GGCC thereby keeping a purine residue at -3 position. The second A-motif downstream of AUG was similarly mutated to GGCCC. Interestingly, the mutation of upstream A-motif had a 2-fold reduction effect on translation inhibition of TIE a3. In contrast, mutation of the downstream A-motif does not affect TIE a3 inhibition (Fig. 7B). Additionally, we confirmed the implication of upstream A-motif in vivo with HEK293T cell line using plasmids with wild type a3 and the mutant of AAAA107 into GGCC (Fig. 7B). The AAAA107 mutant reduces the inhibitory efficiency of TIE a3 by 2.5 times compared to wild type a3. Therefore, we show that the A-motif upstream of the AUG is critical for translation inhibition and most probably because it is required for eIF2D recruitment.

\section{TIE a3 mediated $80 \mathrm{~S}$ formation is cycloheximide-resistant}

To further characterize the molecular mechanism of TIE a3-mediated inhibition, we performed sucrose gradient analysis with TIE a3 in the presence of different specific 
translation inhibitors (Fig. 8). Using GMP-PNP, a non-hydrolysable analogue of GTP that prevents subunit joining, a canonical 48S ribosome accumulates as expected on both TIE a3 and the control (Eliseev et al., 2018) (Fig. 8). With cycloheximide, a translocation inhibitor that binds the E-site of the ribosome (Schneider-Poetsch et al., 2010), we observe the accumulation of a homogeneous $80 \mathrm{~S}$ with the control blocked on the initiating codon. Surprisingly, with a3, we obtained an unusual profile with an $80 \mathrm{~S}$ complexes and complexes heavier complexes than normal $80 \mathrm{~S}$ complexes (indicated with an arrow). The nature of these complexes is unknown but we speculate that they correspond to multiple stalled ribosomes on TIE a3 (Fig. 8). Interestingly, with geneticin, an A-site inhibitor that prevents 80S ribosome translocation (Vicens and Westhof, 2003), we observe the expected accumulation of a homogeneous $80 \mathrm{~S}$ complex for both TIE a3 and control mRNAs (Fig. 8). This suggests that cycloheximide blockage is partially inefficient with TIE a3. One explanation of the heavier complexes observed with a3 in the presence of cycloheximide could be that multiple ribosomes are assembled and blocked on the two uAUGs and the main AUG (Fig. 8). However, this possibility is ruled out by our previous toe printing analysis on TIE a3 mRNA that shows that a single toe print on UAUG111 is detected in the presence of cylcoheximide (Fig. 3B). Moreover, we observe the expected $80 \mathrm{~S}$ complex with geneticin confirming that there is only one initiation site on this mRNA. Therefore, another explanation would be that we are indeed observing translating ribosomes that partially escape blockage by cycloheximide. Cycloheximide binds in the E-site of the ribosome (Garreau de Loubresse et al., 2014). Interestingly, cryo-EM structures have shown that eIF2D also binds in the E-site. The presence of eIF2D in the pre-initiation complex might overlap the cylcoheximide binding site and thereby prevent at least partially the access of cycloheximide to its binding site on the ribosome (Weisser et al., 2017). Although preliminary, this explanation could bring another argument in favour of the implication of eIF2D in TIE a3-mediated inhibition. 


\section{Discussion}

Our study has shown that two HoxA mRNAs, a3 and a11, are regulated by different mechanisms to ensure the inhibition of cap-dependent translation and allowed us to propose two distinct models for their mode of action (Fig. 9). First, we have shown that TIE elements can function in vitro using cell-free translation extracts. We then confirmed the results obtained with these extracts using in vivo assays in several cell lines. Our findings suggest that a3 inhibits translation by a uORF which is translated through the whole 5'UTR of Hox a3 mRNA producing a small protein of size $9 \mathrm{KDa}$. Interestingly, the alignment of Hox a3 TIE element shows a conservation of the uAUG111 (highlighted in red box) among different species. In contrast to the localisation of the uAUG that is highly conserved, the coding sequence of the uORF is not conserved among species (Fig. S7A). Indeed, uORFs have been recognized as regulators of translation for number of cellular mRNAs (Barbosa et al., 2013). For instance, four uORFs in the 5' leader of GCN4 mRNA restrict the flow of scanning ribosomes from the cap site to the GCN4 initiation codon (Dever et al., 2016; Hinnebusch, 1993). The uORF in AdoMetDC mRNA generates a nascent hexapeptide that interacts with its translating ribosome to suppress translation of AdoMetDC RNA in a cell-specific manner (Uchiyama-Kadokura et al., 2014). Interestingly, our data indicates that eIF2D is required in TIE a3 mode of action. A Recent study has shown that ATF4 mRNA translation is induced by eIF2D and its homologue DENR during integrated stress response (Vasudevan et al., 2020). In this case, eIF2D requires its RNA binding motif to mediate translation of ATF4 mRNA through its 5' leader sequence consisting of multiple uORFs (Vasudevan et al., 2020). Moreover, it has been shown that eIF2 $\alpha$-phosphorylation during stages of embryonic development promotes translation from uORFs (Friend et al., 2015). Therefore, canonical cap-dependent translation initiation with eIF2 is not possible during embryonic development. The cap-dependent translation initiation of uORF from TIE a3 might use eIF2D as an alternative to replace inactive phosphorylated eIF2 to promote uORF translation. So far, the only cis-acting sequence that has been clearly defined on an mRNA for specific eIF2D recruitment is an A-rich motif upstream of the start codon (Dmitriev et al., 2010). We showed that TIE a3 contains such an A-motif upstream of the UORF that is critical for TIE function (Fig. 7). Other reports showed that eIF2D would form initiation complexes on leaderless and A-rich 5'UTRs (Akulich et al., 2016; Dmitriev et al., 2010). In TIE a3, mass spectrometry analysis enabled us to demonstrate that eIF2D is present only in pre-initiation complexes programmed with TIE a3. Interestingly, we also showed that cycloheximide does not fully 
inhibit TIE a3 uORF translation as expected which suggests that eIF2D might at least partially interfere with cylcoheximide binding in the ribosomal E-site. In fact, other examples of partial cycloheximide resistance of specific mRNAs have been recently described (Kearse et al., 2019). In these cases, cycloheximide resistance occurs due to queuing of scanning preinitiation complexes in response to slowly elongating ribosomes from non-AUG codons. Regarding TIE a11, the ribosome recognizes a combination of two cis-acting elements in the 5'UTR (Fig. 9). (i) A start-stop codon combination located at positions 84-89 and (ii) a long highly stable GC-rich helical structure (SL) located at +20 downstream of the uAUG (by convention, the A from the AUG being +1). These two elements act in synergy to promote the stalling of an $80 \mathrm{~S}$ complex upstream of the SL. This is a reminiscent of a similar mechanism that has been described in the Arabidopsis thaliana NIP5.1 5'UTR mRNA that contains an AUG-stop that regulates translation of the main ORF through a ribosome stalling mechanism and mRNA degradation (Tanaka et al., 2016). This mechanism requires only the start-stop codons. In the case of TIE a11, an additional cis-element is required for ribosome stalling, namely the stable SL that is present downstream of the AUG-stop. A ribosome that is stalled with a stop codon in the A site, in other words an empty A site without any tRNA, is usually the signal for recruitment of the release factors to dissociate the ribosomal subunits from the mRNA. With our cell-free translation assay and sucrose gradient analysis, we showed that the stalled 80S programmed with TIE a11 is very stable and does not dissociate (Fig. 5C). A possible explanation for the stability of this complex could be that the SL blocks the access of the release factors to the empty A site thereby preventing ribosome dissociation (Brown et al., 2015). Interestingly, the alignment of TIE a11 among different species shows that the startstop combination (highlighted in red) lacks conservation (Fig. S7B). Some species possess a substitution of the start codon AUG to AUG-like codons such GUG or a mutation of stop codon that leads to a longer uORF. In contrast, the SL (104-154) (highlighted in green) remains highly conserved suggesting a functional significance (Fig. S7B). Accordingly, we have shown that the sole SL is strong enough to impede scanning by the pre-initiation complex. Indeed, secondary structures in the 5'UTR have been shown to inhibit translation like the case of a conserved stem loop structure in the 5'UTR of TGF- $\beta 1$ mRNA (Jenkins et al., 2010). Therefore, in various species, TIE a11 might use different combinations of cisacting elements in order to block cap-dependent translation, the common cis-acting element between all species being the SL that is conserved.

As previously described, the IRES in Hox a11 mRNA requires the presence of the ribosomal protein RpL38 while that in Hox a3 mRNA is RpL38-independent (Kondrashov et al., 2011). 
Our probing experiments revealed that the folding of both a3 and a11 TIE elements is independent of the presence of IRES suggesting that their mode of action does not depend on the IRES. TIE may have evolved in such a way to favour the translation from the downstream IRES hence justifying why there is variation in terms of sequence and mechanism but same inhibitory effect. This unique combination of an inhibitor of canonical translation mechanism and the activator of specialized translation sets an interesting point on how the 5'UTR elements confer ribosome specificity to translation (Xue et al., 2015). Importantly, the acquisition of these TIE elements in subsets of Hox mRNAs enables an additional layer of regulatory control between the canonical translation and the IRES-dependent one. One intriguing study would be to determine how other TIE elements a4 and a9 inhibit translation and whether there are common functional features amongst all Hox mRNAs. Beyond Hox mRNAs, our data on eIF2D suggests a specific role in translation initiation and it would be interesting to decipher its precise role at the molecular level. More precisely, determining how uORF length, codon composition and consensus sequences may influence the role of eIF2D in the initiation process on uORFs. Future studies will be required to fully understand the role of eIF2D in translation initiation of specific mRNAs.

\section{Acknowledgments}

This work was funded by 'Agence Nationale pour la Recherche' (Ribofluidix, ANR-17CE12-0025-01, by University of Strasbourg and by the 'Centre National de la Recherche Scientifique'. We would like to thank Dr. Maria Barna for sharing sequences of Hox a3 and 11 transcripts. We are grateful to Dr. Christine Allmang, Hassan Hayek, Antonin Tidu, Aurélie Janvier, Aurélie Durand for technical assistance, Philippe Hamman, Johana Chicher, Lauriane Kuhn for Mass spectrometry analysis, Dr. Mireille Baltzinger and Dr. Pascale Romby for support and useful discussions on the project. We would also like to thank Dr. Sebastien Pfeffer for the pmirGLO plasmid.

\section{Author contributions}

FM, GE and FA designed the experimental strategy, FA performed all the experiments with the technical assistance of LS. FA, GE and FM interpreted the results and wrote the manuscript. 


\section{References}

Adomavicius, T., Guaita, M., Zhou, Y., Jennings, M.D., Latif, Z., Roseman, A.M., and Pavitt, G.D. (2019). The structural basis of translational control by eIF2 phosphorylation. Nat.

Commun. 10, 2136.

Ahmed, Y.L., Schleich, S., Bohlen, J., Mandel, N., Simon, B., Sinning, I., and Teleman, A.A. (2018). DENR-MCTS1 heterodimerization and tRNA recruitment are required for translation reinitiation. PLoS Biol. 16, e2005160.

Akulich, K.A., Andreev, D.E., Terenin, I.M., Smirnova, V. V., Anisimova, A.S., Makeeva, D.S., Arkhipova, V.I., Stolboushkina, E.A., Garber, M.B., Prokofjeva, M.M., et al. (2016). Four translation initiation pathways employed by the leaderless mRNA in eukaryotes. Sci. Rep. 6, 37905.

Alexander, T., Nolte, C., and Krumlauf, R. (2009). Hox Genes and Segmentation of the Hindbrain and Axial Skeleton. Annu. Rev. Cell Dev. Biol. 25, 431-456.

Aylett, C.H.S., Boehringer, D., Erzberger, J.P., Schaefer, T., and Ban, N. (2015). Structure of a yeast 40S-eIF1-eIF1A-eIF3-eIF3j initiation complex. Nat. Struct. Mol. Biol. 22, 269-271. Barbosa, C., Peixeiro, I., and Romão, L. (2013). Gene Expression Regulation by Upstream Open Reading Frames and Human Disease. PLoS Genet. 9, e1003529.

Brown, A., Shao, S., Murray, J., Hegde, R.S., and Ramakrishnan, V. (2015). Structural basis for stop codon recognition in eukaryotes. Nature 524, 493-496.

Chicher, J., Simonetti, A., Kuhn, L., Schaeffer, L., Hammann, P., Eriani, G., and Martin, F. (2015). Purification of mRNA-programmed translation initiation complexes suitable for mass spectrometry analysis. Proteomics 15, 2417-2425.

Dever, T.E., Kinzy, T.G., and Pavitt, G.D. (2016). Mechanism and regulation of protein synthesis in Saccharomyces cerevisiae. Genetics 203, 65-107.

Dmitriev, S.E., Terenin, I.M., Andreev, D.E., Ivanov, P.A., Dunaevsky, J.E., Merrick, W.C., and Shatsky, I.N. (2010). GTP-independent tRNA delivery to the ribosomal P-site by a novel eukaryotic translation factor. J. Biol. Chem. 285, 26779-26787.

Eliseev, B., Yeramala, L., Leitner, A., Karuppasamy, M., Raimondeau, E., Huard, K., Alkalaeva, E., Aebersold, R., and Schaffitzel, C. (2018). Structure of a human cap-dependent 48S translation pre-initiation complex. Nucleic Acids Res. 46, 2678-2689.

Fletcher, L., Corbin, S.D., Browning, K.S., and Ravel, J.M. (1990). The absence of a m7G cap on beta-globin mRNA and alfalfa mosaic virus RNA 4 increases the amounts of initiation factor 4F required for translation. J. Biol. Chem. 265, 19582-19587. 
Friend, K., Brooks, H.A., Propson, N.E., Thomson, J.A., and Kimble, J. (2015). Embryonic stem cell growth factors regulate eIF2 $\alpha$ phosphorylation. PLoS One 10, e0139076.

Garreau de Loubresse, N., Prokhorova, I., Holtkamp, W., Rodnina, M. V., Yusupova, G., and Yusupov, M. (2014). Structural basis for the inhibition of the eukaryotic ribosome. Nature $513,517-522$.

Gross, L., Vicens, Q., Einhorn, E., Noireterre, A., Schaeffer, L., Kuhn, L., Imler, J.-L., Eriani, G., Meignin, C., and Martin, F. (2017). The IRES5'UTR of the dicistrovirus Cricket Paralysis Virus is a type III IRES containing an essential pseudoknot structure. Nucleic Acids Res. 45, 8993-9004.

Hinnebusch, A.G. (1993). Gene-specific translational control of the yeast GCN4 gene by phosphorylation of eukaryotic initiation factor 2. Mol. Microbiol. 10, 215-223.

Hinnebusch, A.G. (2014). The scanning mechanism of eukaryotic translation initiation. Annu. Rev. Biochem. 83, 779-812.

Jenkins, R.H., Bennagi, R., Martin, J., Phillips, A.O., Redman, J.E., and Fraser, D.J. (2010). A conserved stem loop motif in the 59untranslated region regulates transforming growth factor- $\beta 1$ translation. PLoS One 5, e12283.

Karabiber, F., McGinnis, J.L., Favorov, O. V, and Weeks, K.M. (2013). QuShape: rapid, accurate, and best-practices quantification of nucleic acid probing information, resolved by capillary electrophoresis. RNA 19, 63-73.

Kearse, M.G., Goldman, D.H., Choi, J., Nwaezeapu, C., Liang, D., Green, K.M., Goldstrohm, A.C., Todd, P.K., Green, R., and Wilusz, J.E. (2019). Ribosome queuing enables non-AUG translation to be resistant to multiple protein synthesis inhibitors. Genes Dev. 33, 871-885. Kondrashov, N., Pusic, A., Stumpf, C.R., Shimizu, K., Hsieh, A.C., Xue, S., Ishijima, J., Shiroishi, T., and Barna, M. (2011). Ribosome-mediated specificity in Hox mRNA translation and vertebrate tissue patterning. Cell 145, 383-397.

Kozak, M. (1986). Point mutations define a sequence flanking the AUG initiator codon that modulates translation by eukaryotic ribosomes. Cell 44, 283-292.

Laemmli, U.K. (1970). Cleavage of structural proteins during the assembly of the head of bacteriophage T4. Nature 227, 680-685.

Leppek, K., Fujii, K., Quade, N., Susanto, T.T., Boehringer, D., Lenarčič, T., Xue, S., Genuth, N.R., Ban, N., and Barna, M. (2020). Gene- and Species-Specific Hox mRNA Translation by Ribosome Expansion Segments. Mol. Cell S1097-2765, 30730-30739. Martin, F., Barends, S., Jaeger, S., Schaeffer, L., Prongidi-Fix, L., and Eriani, G. (2011). Capassisted internal initiation of translation of histone H4. Mol Cell 41, 197-209. 
Martin, F., Ménétret, J.F., Simonetti, A., Myasnikov, A.G., Vicens, Q., Prongidi-Fix, L., Natchiar, S.K., Klaholz, B.P., and Eriani, G. (2016). Ribosomal 18S rRNA base pairs with mRNA during eukaryotic translation initiation. Nat. Commun. 7, 12622.

Mathews, D.H., Turner, D.H., and Watson, R.M. (2016). RNA secondary structure prediction. Curr. Protoc. Nucleic Acid Chem. 2016, 11.2.1-11.2.19.

Merrick, W.C., and Pavitt, G.D. (2018). Protein synthesis initiation in eukaryotic cells. Cold Spring Harb. Perspect. Biol. 10, a033092.

Oh, S.K., Scott, M.P., and Sarnow, P. (1992). Homeotic gene Antennapedia mRNA contains 5 '-noncoding sequences that confer translational initiation by internal ribosome binding. Genes Dev. 6, 1643-1653.

Pelletier, J., and Sonenberg, N. (2019). The Organizing Principles of Eukaryotic Ribosome Recruitment. Annu. Rev. Biochem. 88, 307-335.

Phinney, D.G., Gray, A.J., Hill, K., and Pandey, A. (2005). Murine mesenchymal and embryonic stem cells express a similar Hox gene profile. Biochem. Biophys. Res. Commun. $338,1759-1765$.

Prongidi-Fix, L., Schaeffer, L., Simonetti, A., Barends, S., Ménétret, J.-F., Klaholz, B.P., Eriani, G., and Martin, F. (2013). Rapid purification of ribosomal particles assembled on histone H4 mRNA: a new method based on mRNA-DNA chimaeras. Biochem. J. 449, 719728.

Schneider-Poetsch, T., Ju, J., Dang, Y., Bhat, S., Green, R., Shen, B., Merrick, W.C., Eyler, D.E., and Liu, J.O. (2010). Inhibition of eukaryotic translation elongation by cycloheximide and lactimidomycin. Nat. Chem. Biol. 6, 209-217.

Shirokikh, N.E., and Preiss, T. (2018). Translation initiation by cap-dependent ribosome recruitment: Recent insights and open questions. Wiley Interdiscip. Rev. RNA 9, e1473. Skabkin, M.A., Skabkina, O. V., Dhote, V., Komar, A.A., Hellen, C.U.T., and Pestova, T. V. (2010). Activities of Ligatin and MCT-1/DENR in eukaryotic translation initiation and ribosomal recycling. Genes Dev. 24, 1787-1801.

Skabkin, M.A., Skabkina, O. V., Hellen, C.U.T., and Pestova, T. V. (2013). Reinitiation and other unconventional posttermination events during eukaryotic translation. Mol. Cell 51, 249264.

Tanaka, M., Sotta, N., Yamazumi, Y., Yamashita, Y., Miwa, K., Murota, K., Chiba, Y., Hirai, M.Y., Akiyama, T., Onouchi, H., et al. (2016). The Minimum Open Reading Frame, AUGStop, Induces Boron-Dependent Ribosome Stalling and mRNA Degradation. Plant Cell 28, 2830-2849. 
Thoma, C., Bergamini, G., Galy, B., Hundsdoerfer, P., and Hentze, M.W. (2004).

Enhancement of IRES-mediated translation of the c-myc and BiP mRNAs by the poly(A) tail is independent of intact eIF4G and PABP. Mol Cell 15, 925-935.

Uchiyama-Kadokura, N., Murakami, K., Takemoto, M., Koyanagi, N., Murota, K., Naito, S., and Onouchi, H. (2014). Polyamine-responsive ribosomal arrest at the stop codon of an upstream open reading frame of the AdoMetDC1 gene triggers nonsense-mediated mRNA decay in Arabidopsis thaliana. Plant Cell Physiol. 55, 1556-1567.

Vaidya, A.T., Lomakin, I.B., Joseph, N.N., Dmitriev, S.E., and Steitz, T.A. (2017). Crystal Structure of the C-terminal Domain of Human eIF2D and Its Implications on Eukaryotic Translation Initiation. J. Mol. Biol. 429, 2765-2771.

Varland, S., Osberg, C., and Arnesen, T. (2015). N-terminal modifications of cellular proteins: The enzymes involved, their substrate specificities and biological effects.

Proteomics 15, 2385-2401.

Vasudevan, D., Neuman, S.D., Yang, A., Lough, L., Brown, B., Bashirullah, A., Cardozo, T., and Ryoo, H.D. (2020). Translational induction of ATF4 during integrated stress response requires noncanonical initiation factors eIF2D and DENR. Nat. Commun. 11, 4677.

Vicens, Q., and Westhof, E. (2003). Crystal structure of geneticin bound to a bacterial $16 \mathrm{~S}$ ribosomal RNA A site oligonucleotide. J. Mol. Biol. 326, 1175-1188.

Wakiyama, M., Kaitsu, Y., and Yokoyama, S. (2006). Cell-free translation system from Drosophila S2 cells that recapitulates RNAi. Biochem. Biophys. Res. Commun. 343, 10671071.

Weisser, M., Schäfer, T., Leibundgut, M., Böhringer, D., Aylett, C.H.S., and Ban, N. (2017). Structural and Functional Insights into Human Re-initiation Complexes. Mol. Cell 67, 447456.e7.

Xue, S., Tian, S., Fujii, K., Kladwang, W., Das, R., and Barna, M. (2015). RNA regulons in Hox 5' UTRs confer ribosome specificity to gene regulation. Nature 517, 33-38.

Ye, X., Fong, P., Iizuka, N., Choate, D., and Cavener, D.R. (1997). Ultrabithorax and Antennapedia 5' untranslated regions promote developmentally regulated internal translation initiation. Mol. Cell. Biol. 17, 1714-1721.

Young, D.J., and Guydosh, N.R. (2019). Hcr1/eIF3j Is a 60S Ribosomal Subunit Recycling Accessory Factor In Vivo. Cell Rep. 28, 39-50.e4.

Young, D.J., Makeeva, D.S., Zhang, F., Anisimova, A.S., Stolboushkina, E.A., Ghobakhlou, F., Shatsky, I.N., Dmitriev, S.E., Hinnebusch, A.G., and Guydosh, N.R. (2018).

Tma64/eIF2D, Tma20/MCT-1, and Tma22/DENR Recycle Post-termination 40S Subunits In 
bioRxiv preprint doi: https://doi.org/10.1101/2021.01.19.427285; this version posted January 21, 2021. The copyright holder for this preprint (which was not certified by peer review) is the author/funder, who has granted bioRxiv a license to display the preprint in perpetuity. It is made available under aCC-BY 4.0 International license.

Vivo. Mol. Cell 71, 761-774. e5. 


\section{Figure Legends}

- Figure 1: TIE-mediated inhibition is recapitulated in RRL and does not require full length TIEs.

A. Three capped mRNAs were used to test TIE-mediated inhibition in vitro. TIE a3 and TIE a11 were placed upstream of the 5'UTR of $\beta$-globin and the Renilla luciferase coding sequence. Translation assays were performed in vitro using RRL at an mRNA concentration of $50 \mathrm{nM}$, which enables sub-saturating conditions. The relative expression of Luciferase protein reflects the efficiency of translation inhibition by TIE a3 and TIE a11. Values were normalized to that of the control (w/o TIE) which corresponds to normal expression without inhibition and was set to $100 \%{ }^{* *} \mathrm{p}<0.01$ (t-test as compared to w/o TIE) $\mathrm{n}=3$. Experiments were performed in triplicates. B. Sequential deletions in the 5' extremity of TIE a3 and TIE a11 constructs were performed to assay their effect on translation. Values of translation expression were normalized to that of the control (w/o TIE). Experiments were performed in triplicates. The percentages of inhibition for each TIE are indicated in the histogram. $* * \mathrm{p}<0.01$ (t-test as compared to w/o TIE) $\mathrm{n}=3$. Experiments were performed in triplicates.

- Figure 2: the secondary structural models of TIE a3 and TIE a11 reveal distinct structures.

The structures of (A) TIE a3 (170 nucleotides) and (B) TIE a11 (216 nucleotides) were obtained by chemical probing using base-specific reagents, DMS and CMCT. After modifications, reverse transcription was performed using fluorescently labelled primers to determine the position of modified nucleotides. Experiments were performed in triplicates. Reactivities are shown as average reactivity from three independent experiments. A representation of reactivities is assigned as colour code depending on a range of values as shown in the figure legend on the right. Reactivity values for each nucleotide with corresponding standard deviations are shown in supplementary figures (S2A, S2B, S2C, and S2D).

- Figure 3: upstream AUG111 in TIE a3 is essential for inhibition.

(A) Substitution mutations in UAUG111and uAUG123 to UAC in TIE a3 were performed. Constructs with the corresponding mutations were translated in RRL and luciferase assay was performed to evaluate the effect of mutation on translation efficiency as previously described. 
$* * \mathrm{p}<0.01$ (t-test as compared to construct w/o TIE). $\mathrm{n}=3$. Experiments were performed in triplicates (B) Toe printing analysis of ribosomal assembly on two mRNAs, TIE a3 Wt and the mutant of upstream (AUG/UAC)111. Initiation complexes were assembled in RRL extracts in the absence or presence of translation inhibitors: cycloheximide and GMP-PNP. Reaction samples were separated on $8 \%$ denaturing PAGE together with the appropriate sequencing ladder. Toe-print positions were counted starting on the A+1 of the AUG codon at +16 position. Full-length cDNAs are indicated by an arrow at the top of the gel.

\section{- Figure 4: the UAUG111 in TIE a3 is translated through 5'UTR of Hox a3.}

(A) Three transcripts were used for this experiment: full length 5'UTR of Hox a3, a deletion mutant at nucleotide $\mathrm{G}_{333}$ in IRES a3 and a control transcript without TIE. To test the translation of $\mathrm{UORF}$ in TIE a3 starting form uAUG111, a deletion of G in IRES a3 at position 333 was performed to create a longer uORF that is in the same frame as the ORF of Renilla luciferase to create an $\mathrm{N}$-terminally extended luciferase. Transcripts were translated in vitro in RRL and products were loaded on 10\% SDS-PAGE in the presence of ${ }^{35} \mathrm{~S}$-Methionine (B) In vivo luciferase assays in two embryonic cells lines; HEK293FT (left) and C3H10T1/2 (right). Reporter constructs in pmirGlo containing TIE a3, u(AUG/UAC)111, and without TIE, were transfected in the two indicated cell lines. Renilla luciferase expression was normalized to the control (w/o TIE), which was set to $100 \%$. ${ }^{* *} \mathrm{p}<0.01$ (t-test as compared to empty plasmid (w/o TIE). Experiments were performed in triplicates $n=3$

\section{- Figure 5: a start-stop uORF in TIE a11 stalls an 80S upstream of a highly stable structure.}

(A) Mutational analysis of uAUGs in TIE a11. Three transcripts with AUG/UAC mutations were used: M1: (AUG/UAC)84 + (AUG/UAC)159, M2: (AUG/UAC)84 and M3: AUG/UAC159. Transcripts were translated in RRL at $50 \mathrm{nM}$ concentrations and the luciferase expression was normalized to the control (w/o TIE) as previously described. ${ }^{* *} \mathrm{p}<0.01$ (t-test as compared to construct w/o TIE). $\mathrm{n}=3$. Experiments were performed in triplicates. (B) A single substitution (A/G)88 mutation destroys the stop codon UAG87 to UGG in TIE a11, TIE a11 wt and control (w/o TIE) were also translated as references in RRL. Translation products were loaded on 15\% SDS-PAGE. (C) Ribosomal pre-initiation complexes were assembled and analysed on $7-47 \%$ sucrose gradient with [alpha- $\left.{ }^{32} \mathrm{P}\right] \mathrm{GTP}-$ radiolabeled TIE a11 as well as the two mutants of UAUG/UAC at the previously indicated positions in the absence or presence of cycloheximide. Heavy fractions correspond to 
polysomes and lighter fractions correspond to free RNPs.

- Figure 6: distinct profiles for factors involved in TIE-mediated inhibition blocked with cycloheximide.

Mass spectrometry analysis of cycloheximide-blocked translation initiation complexes and on three transcripts: TIE a3, TIE a11 placed upstream of 5'UTR of $\beta$-globin and the 5'UTR of $\beta$ -

globin (control). Graphical representation of proteomics data: protein $\log _{2}$ spectral count fold changes (on the x-axis) and the corresponding adjusted $\log _{10} \mathrm{P}$-values (on the y-axis) are plotted in a pair-wise volcano plot. The significance thresholds are represented by a horizontal dashed line ( $\mathrm{P}$-value $=1.25$, negative-binomial test with Benjamini-Hochberg adjustment) and two vertical dashed lines ( -1.0 -fold on the left and +1.0 -fold on the right). Data points in the upper left and upper right quadrants indicate significant negative and positive changes in protein abundance. Protein names are labelled next to the off-centred spots and they are depicted according to the following color code: red spots are significant hits and black are non-significant with $<10$ spectra. Data points are plotted based on the average spectral counts from triplicate analysis. Three profiles were produced by comparing the proteomics of two transcripts.

- Figure 7: Co-transfection assay of TIE plasmids and siRNA against eIF2D confirms its implication in a3-mediated inhibition. Mutational analysis of A-motif sequences in TIE a3 shows a requirement for an upstream A-motif for efficient inhibition.

(A) Co-transfection assay was performed using pmirGLO plasmids with TIE a3, TIE a11 and w/o TIE with siRNA against eIF2D, eIF4E and non-target pool of siRNA in HEK293 cell line. Plates were incubated for 48 hours followed by cell lysis. Cell lysate was analysed by western blot and luciferase assay. Luciferase activity was normalized compared to control (w/o TIE). ${ }^{* *} \mathrm{p}<0.01$ (t-test as compared to construct w/o TIE). $\mathrm{n}=3$. Experiments were performed in triplicates. Efficiency of silencing of each protein was quantified by western blot analysis for TIE a3 and TIE a11 samples (B) Two sets of mutations were performed on distinct A-motif sequences in TIE a3. The first mutation is AAAA/GGCC107 and the second mutation AAAAA/GGCCC147. The transcripts were in vitro translated in RRL with TIE a3 Wt and control (w/o TIE). Results were confirmed in vivo in HEK293FT cell line. Luciferase activities were normalized to control (w/o TIE). ${ }^{*} \mathrm{p}<0.01$ (t-test as compared to construct w/o TIE). $n=3$. Experiments were performed in triplicates. 


\section{- Figure 8: sucrose gradient analysis of TIE a3 with different inhibitors shows an atypical profile with cycloheximide.}

Ribosomal pre-initiation complexes were assembled and analysed on 7-47\% sucrose gradient with radioactively capped TIE a3 and control (w/o TIE) in the presence of: GMP-PNP and translocation inhibitors cycloheximide and geneticin.

\section{- Figure 9: two distinct models for translational inhibition by TIE a3 and TIE a11.}

A model for TIE a3 suggests a ribosomal assembly on the UAUG111 with a requirement of eIF2D initiation factor. The model for TIE a11 suggests a stalled 80S ribosome on AUG-stop codons combination upstream of a highly stable structure. 


\section{Supplemental Figure Legends}

\section{- Supplemental figure S1: TIE-mediated inhibition recapitulated in different in vitro and in vivo systems.}

(A) (To the left) The intensity of light emitted by Renilla Luciferase protein as a function of control mRNA (w/o TIE) concentration (nM). Emission of light was measured under subsaturating conditions (50-100 $\mathrm{nM}$ mRNA concentration). (Middle panel) The intensity of light emission by RLuc protein relative to different concentrations $(50 \mathrm{nM}$ and $100 \mathrm{nM}$ respectively) of tested mRNA samples TIE a3, TIE a11 and control (w/o TIE). (To the right) Analysis of translation products after in vitro translation in RRL on 10\% SDS PAGE to monitor RLuc expression. Visualization of protein bands was achieved by incorporation of radiolabelled ${ }^{35} \mathrm{~S}$-methionine, which are detected by autoradiography. (B) In vitro translation of TIE a3 and TIE a1 1 transcripts in the presence of $\mathrm{m}^{7} \mathrm{G}_{\mathrm{ppp}} \mathrm{G}$ cap or a non-functional analog $\mathrm{A}_{\mathrm{ppp}} \mathrm{G}$. Three in vitro systems were used: Wheat Germ Extract (WGE), drosophila embryonic cell extract (S2) and HeLa cell extract. All mRNAs were translated in vitro at $50 \mathrm{nM}$ concentrations and RLuc expression was normalized to control (w/o TIE) in each condition. (C) Transfection of reporter plasmids with TIE a3 or TIE a11 in two embryonic cell lines, kidney HEK293FT and mesenchymal C3H10T1/2 cell lines. Renilla luciferase expression was normalized to the control (w/o TIE). ${ }^{* *} \mathrm{p}<0.01$ (t-test as compared to construct w/o TIE). $\mathrm{n}=3$. Experiments were performed in triplicates. (D) SDS PAGE of Renilla expression with 5' deletions in TIE a3 and TIE a11. The gels at the bottom refer to the minimal functional region compared to longest construct that is inactivated by 5 ' deletions.

\section{- Supplemental figure S2: average of reactivities of DMS and CMCT for TIE a3 and TIE a11.}

Probing experiments by DMS and CMCT were performed in triplicates. Figures S2A and S2B represent averages of reactivities of DMS and CMCT for TIE a3 respectively. Figures S2C and S2D represent averages of reactivities of DMS and CMCT for TIE a11 respectively. A scale of 40 nucleotides range was included to determine position of every nucleotide. Standard deviations are shown.

- Supplemental figure S3: upstream AUG111 in TIE a3 is essential for inhibition.

(A) (To the left) AUG-like mutations (AUU, GUG, CUG and ACG) were tested compared to 
wt a3. (To the right) Representation of uAUG111 context in the secondary structure of TIE a3 is shown. A111 and U112 base pair with the A123 and U124 of the second AUG123. Mutants of the uAUG into CUG and GUG with the corresponding compensatory mutagenesis were tested. RLuc expression with different transcripts was normalized to control (w/o TIE). ${ }^{* *} \mathrm{p}<0.01$ (t-test as compared to construct w/o TIE). $\mathrm{n}=3$. Experiments were performed in triplicates. (B) Sucrose gradient analysis of TIE a3 and mutant of upstream (AUG/UAC)111. Ribosomal pre-initiation complexes were assembled and analysed on 7-47\% sucrose gradient with radioactive $\mathrm{m}^{7} \mathrm{G}$-capped TIE $\mathrm{a} 3$ and the mutants of upstream (AUG/UAC)111 in the absence (upper panel) or in the presence of GMP-PNP (lower panel). Heavy fractions correspond to polysomes while the lightest correspond to free RNPs.

\section{- Supplemental figure S4: translation of TIE a3 uORF in different constructs.}

(A) A single nucleotide deletion of A220 in TIE a3 is performed to frameshift the uORF frame to the same as the main Rluc ORF. Another mutation was performed combining this deletion with uAUG mutation of (U/C)112. Transcripts were in vitro translated in RRL and products were loaded on 10\% SDS PAGE. (B) Translation of TIE a3 uORF in Hox a3 mRNA. Hox a3 mRNA (5'UTR+CDS) was translated in vitro to check uORF translation in this context. Products were analysed on $15 \%$ SDS-PAGE.

\section{- Supplemental figure S5: transplanting TIE a11 stem loop structure in globin 5' UTR efficiently inhibits translation of RLuc mRNA.}

The stem loop structure of TIE a11 (104-154) was transplanted in the 5'UTR of $\beta$-globin with 25 nucleotides spanning from each extremity. The three shown transcripts were in vitro translated in RRL at two concentrations, $25 \mathrm{nM}$ and $50 \mathrm{nM}$. Results are represented in relative light unit of Rluc expression.

\section{- Supplemental figure S6: distinct profiles for factors involved in TIE-mediated inhibition blocked with GMP-PNP.}

Mass spectrometry analysis of GMP-PNP-blocked translation initiation complexes and on three transcripts: TIE a3, TIE a11 placed upstream of 5'UTR of $\beta$-globin and the 5'UTR of $\beta$ globin (control). Graphical representation of proteomics data: protein $\log _{2}$ spectral count fold changes (on the x-axis) and the corresponding adjusted $\log _{10}$ P-values (on the y-axis) are plotted in a pair-wise volcano plot. The significance thresholds are represented by a horizontal dashed line $(\mathrm{P}$-value $=1.25$, negative-binomial test with Benjamini-Hochberg adjustment) 
and two vertical dashed lines ( -1.0 -fold on the left and +1.0 -fold on the right). Data points in the upper left and upper right quadrants indicate significant negative and positive changes in protein abundance. Protein names are labelled next to the off-centred spots and they are depicted according to the following color code: red spots are significant hits and black are non-significant with $<10$ spectra. Data points are plotted based on the average spectral counts from triplicate analysis. Three profiles were produced by comparing the proteomics of two transcripts.

\section{- Supplemental figure S7: Alignment of TIE a3 and TIE a11 among different species shows variation in the conservation of the inhibitory elements.}

(A) Nucleotides 1-170 from the mouse TIE a3 sequence were aligned with different species. The position of uAUG in Mus musculus is highlighted in a red box. Accession numbers: $F$. catus: XR_002740526.1, M. musculus: NM_010452.3, M. flaviventris: XM_0279, H. sapiens: XM_011515343.3,M. mulatta:XM_028845931.1,P.Anubis: XM_017956197.2,E. caballus: XM_023639416.1, U. horribilis: XM_026508219.1, C. dingo: XM_025464436.1

Nucleotides 1-216 from the mouse TIE a11 sequence were aligned with different species. The position of uAUG-UAG in Mus Musculus and the insertion of AUG-UAG in Homo sapiens are highlighted in red boxes. Accession numbers: H. sapiens: AF071164.1, M. Mulata: XM_015133828.2, C.dingo: XR_003143092.1, C. griseus: XM_027436289.1, R. norvegicus: XM_008762951.2, E. caballus: XM_023639423.1, M auratus: XM_00508585871.3, M. musculus: NM_010450. 


\section{Figure 1}

A
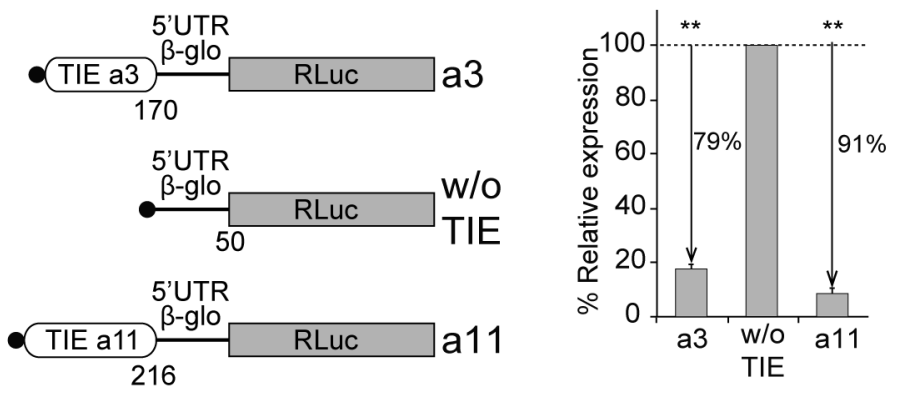

B
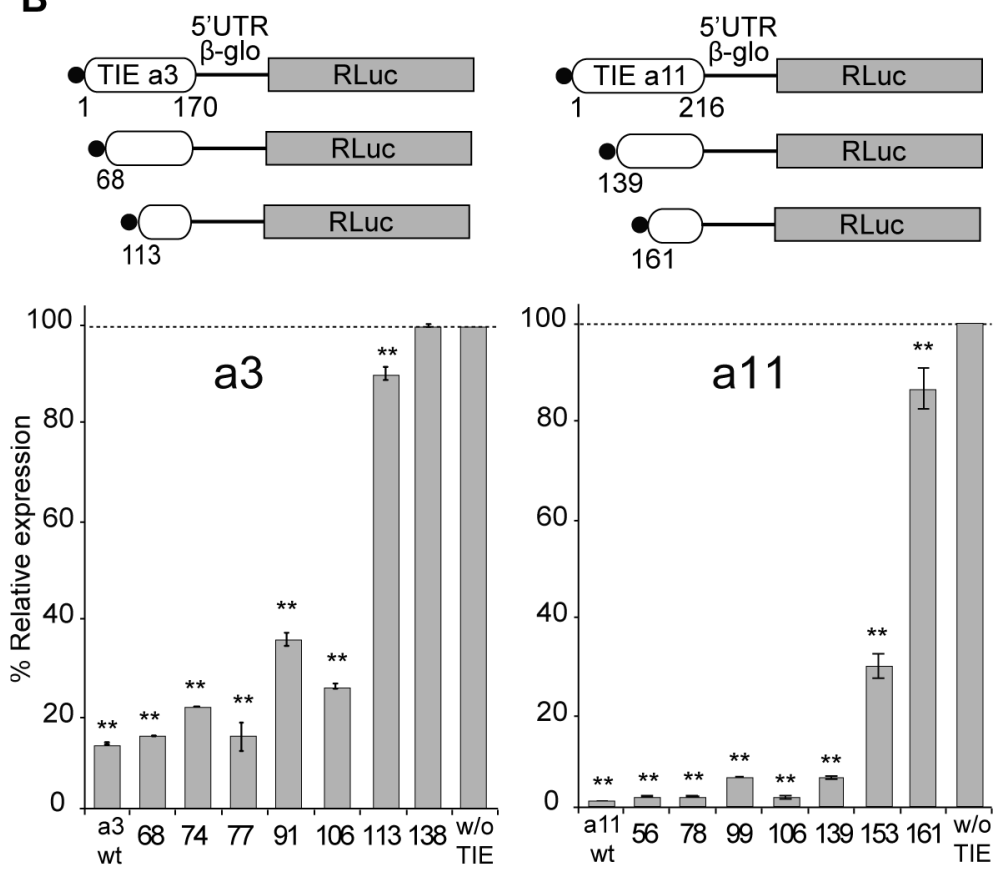


\section{Figure 2}

A

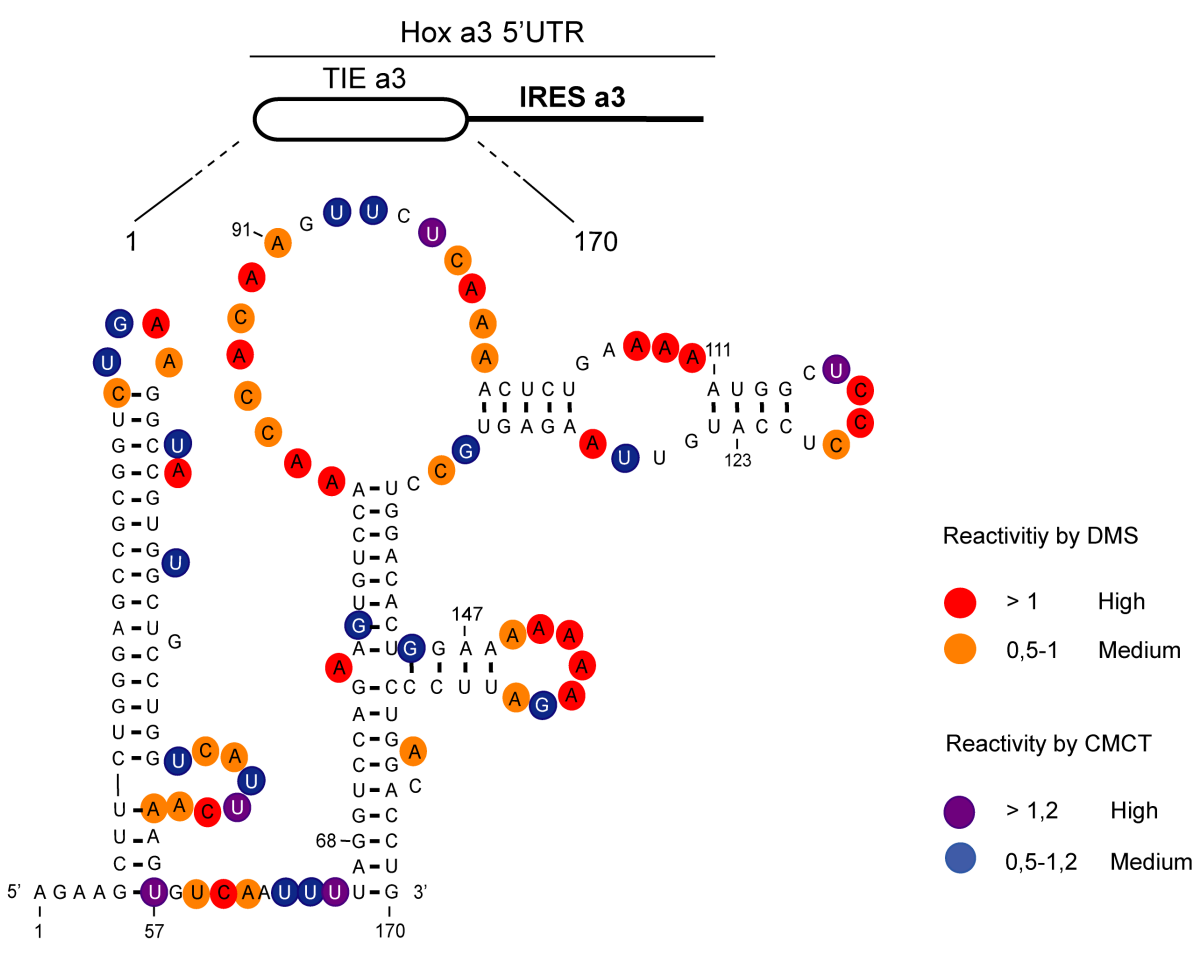

B
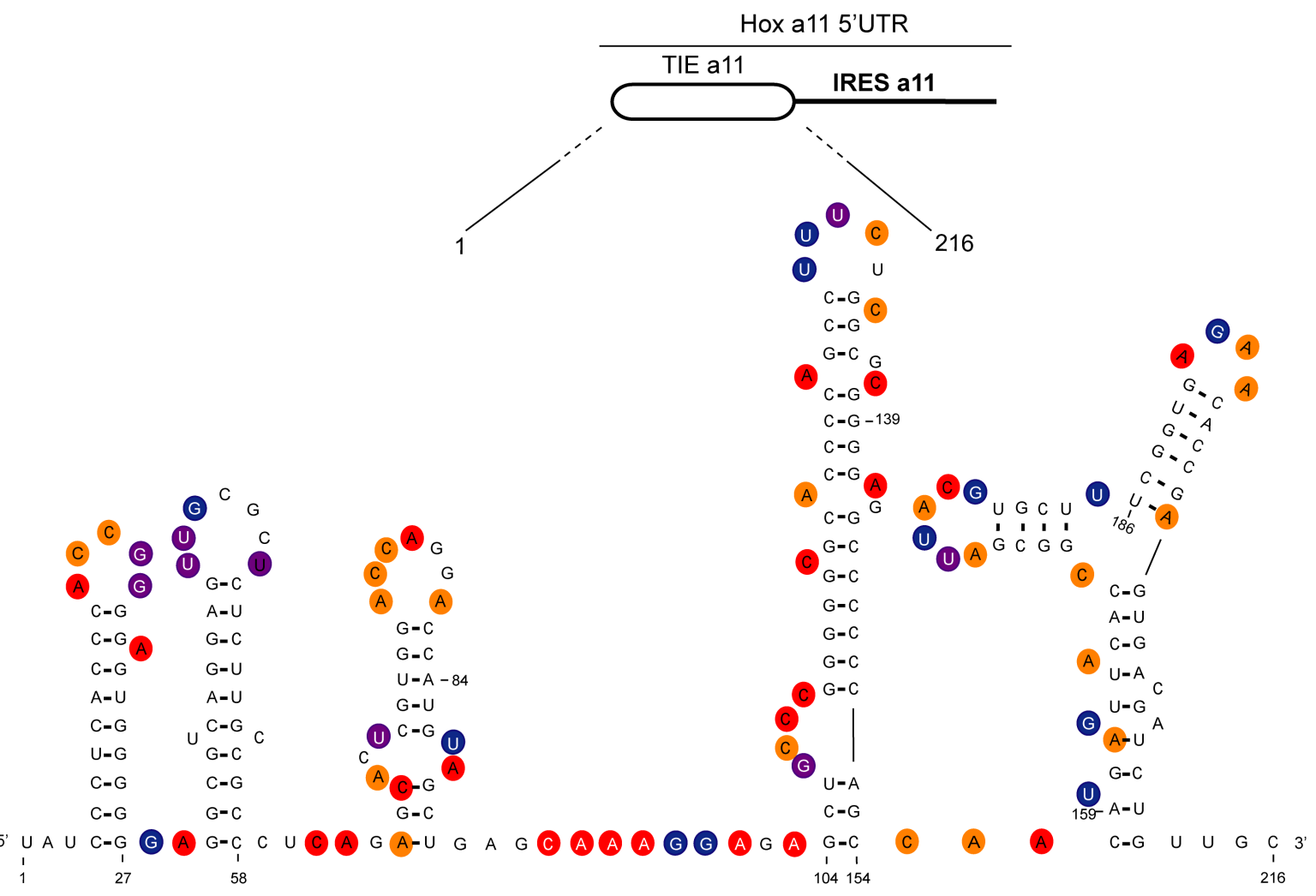
bioRxiv preprint doi: https://doi.org/10.1101/2021.01.19.427285; this version posted January 21, 2021. The copyright holder for this preprint (which was not certified by peer review) is the author/funder, who has granted bioRxiv a license to display the preprint in perpetuity. It is made available under aCC-BY 4.0 International license.

Figure 3

A

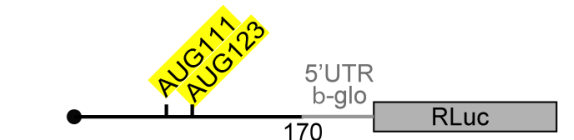

(AUG/UAC)

TIE a3

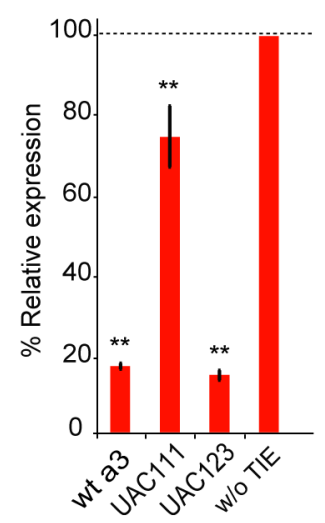

B

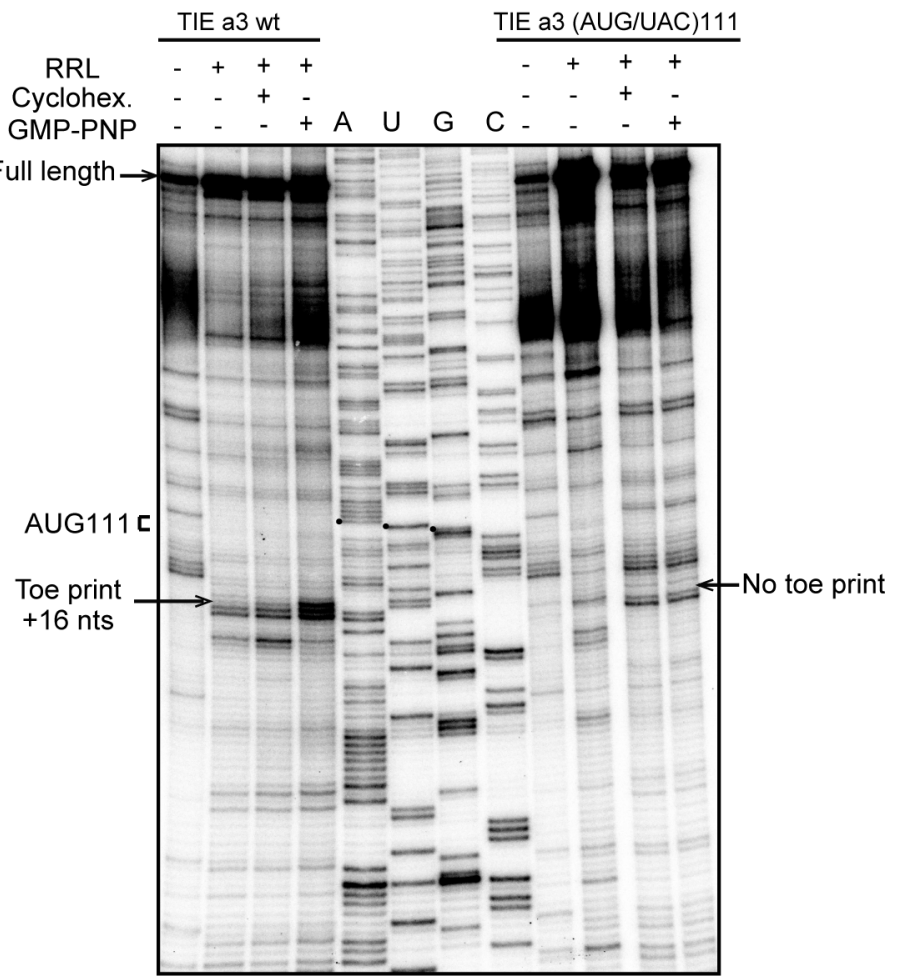




\section{Figure 4}

A
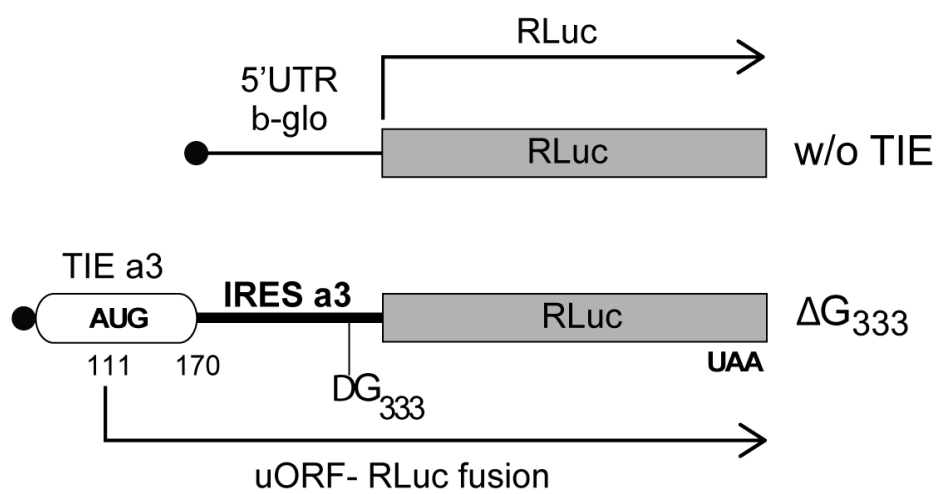

$\Delta \mathrm{G}_{333}$

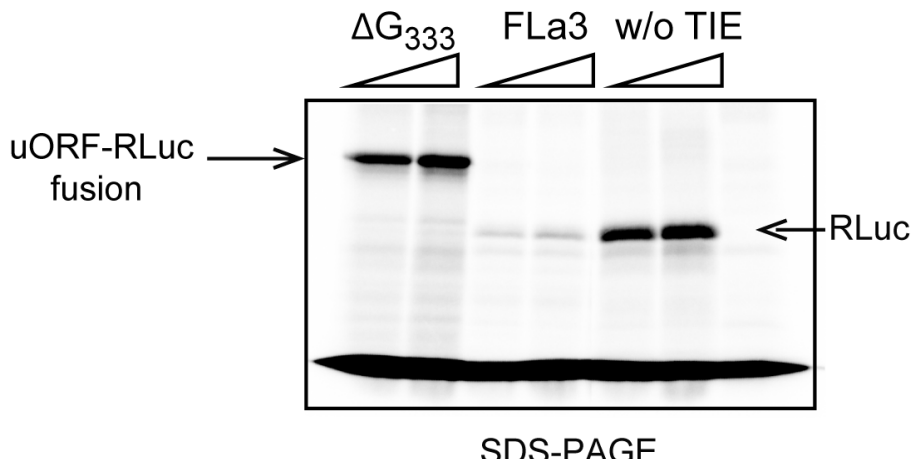

B

HEK293FT cell line

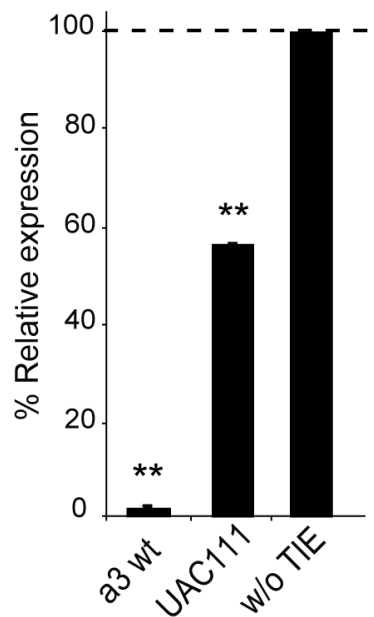

C3H10T1/2 cell line




bioRxiv preprint doi: https://doi.org/10.1101/2021.01.19.427285; this version posted January 21, 2021. The copyright holder for this preprint (which was not certified by peer review) is the author/funder, who has granted bioRxiv a license to display the preprint in perpetuity. It is made available under aCC-BY 4.0 International license.

\section{Figure 5}

A

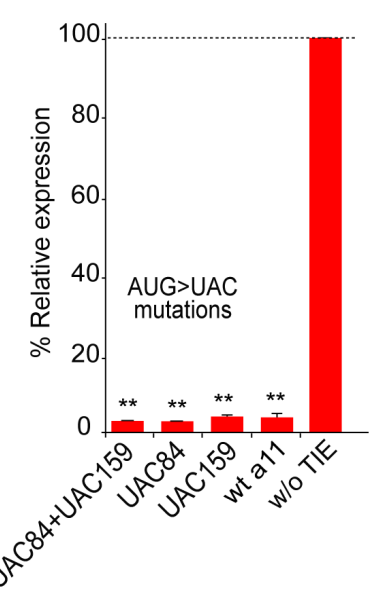

C

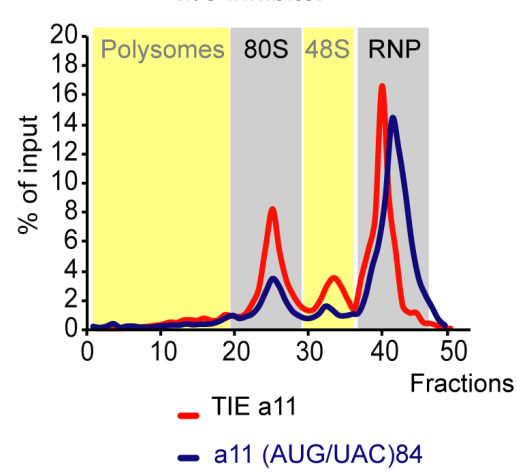

B

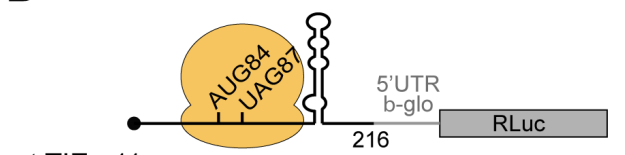

wt TIE a11
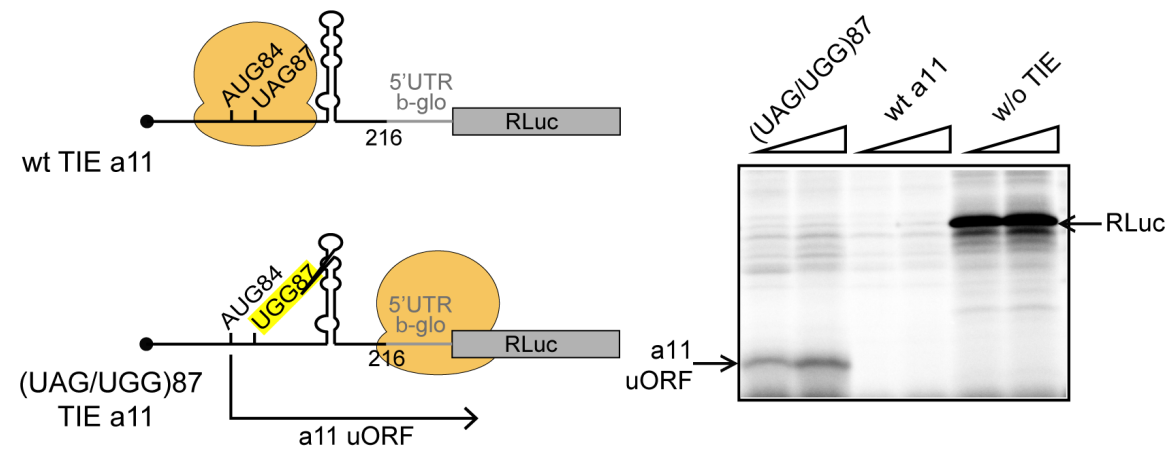

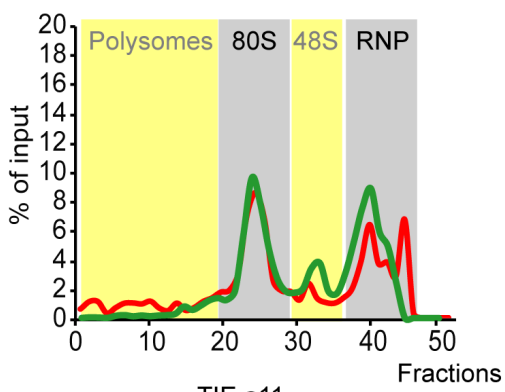

- TIE a11

- a11 (AUG/UAC)159
+ cycloheximide

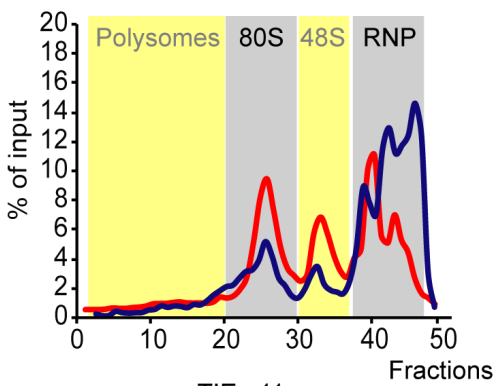

- TIE a11

- a11 (AUG/UAC)84 
bioRxiv preprint doi: https://doi.org/10.1101/2021.01.19.427285; this version posted January 21, 2021. The copyright holder for this preprint (which was not certified by peer review) is the author/funder, who has granted bioRxiv a license to display the preprint in perpetuity. It is made available under aCC-BY 4.0 International license.

\section{Figure 6}
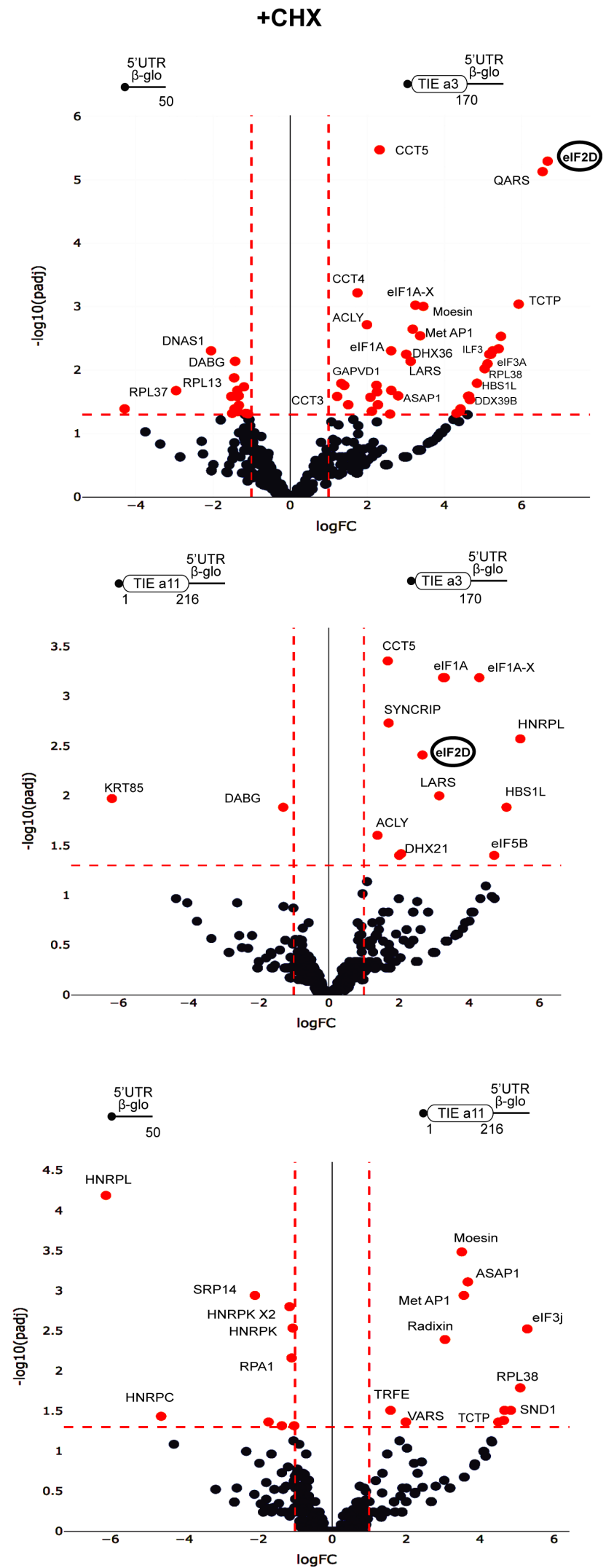
bioRxiv preprint doi: https://doi.org/10.1101/2021.01.19.427285; this version posted January 21, 2021. The copyright holder for this preprint (which was not certified by peer review) is the author/funder, who has granted bioRxiv a license to display the preprint in perpetuity. It is made available under aCC-BY 4.0 International license.

\section{Figure 7}

A

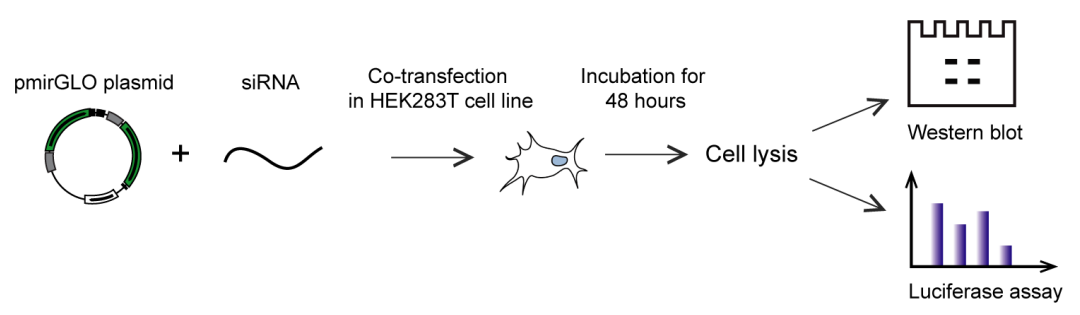

Co-transfection with TIE a3
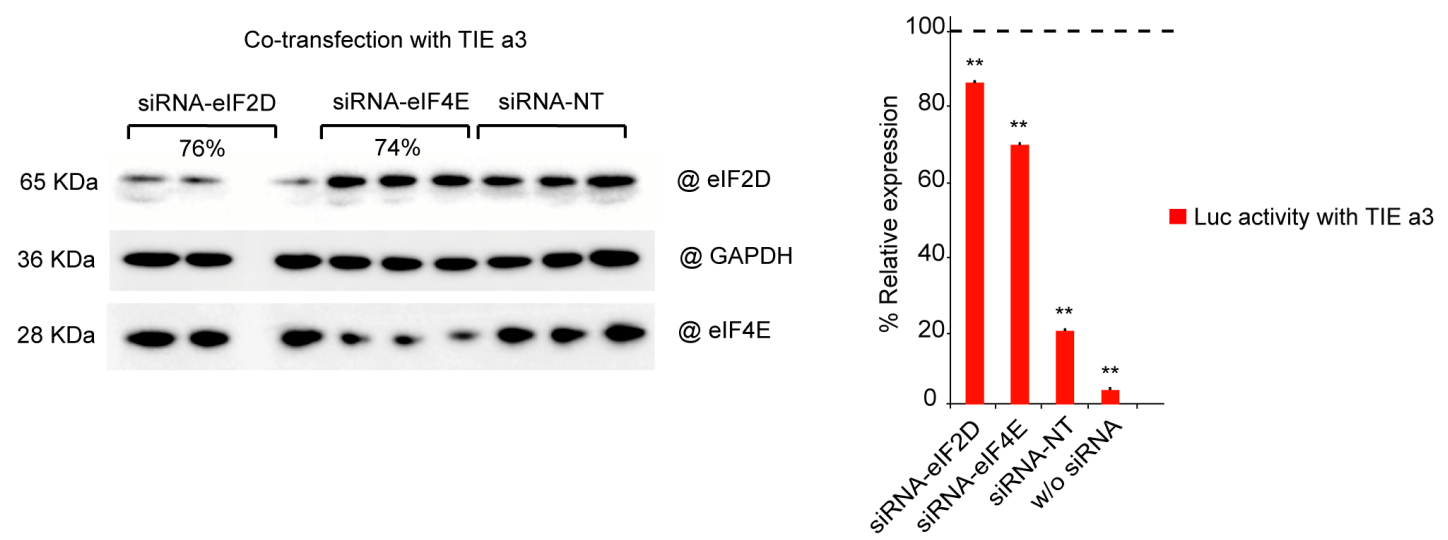

Co-transfection with TIE a11
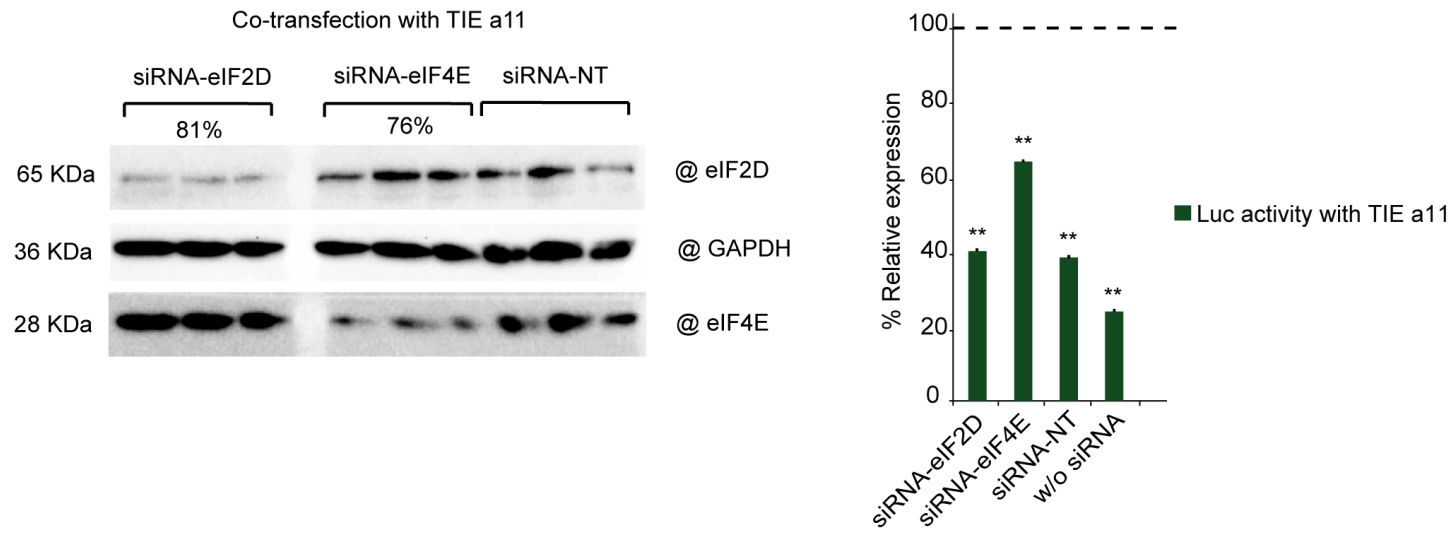

B

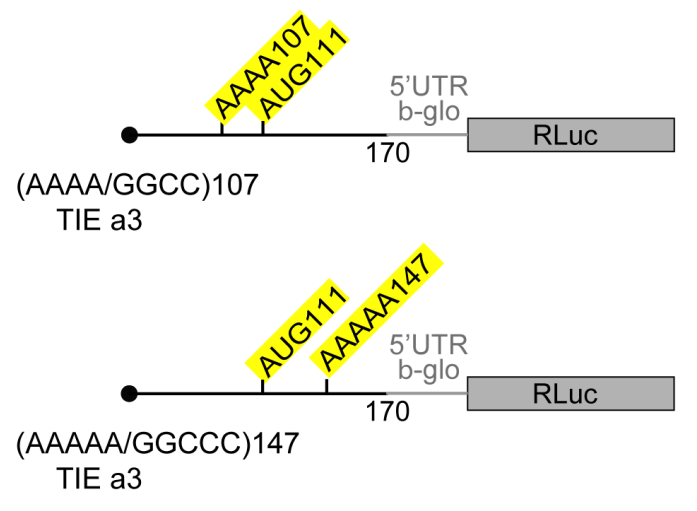

RRL

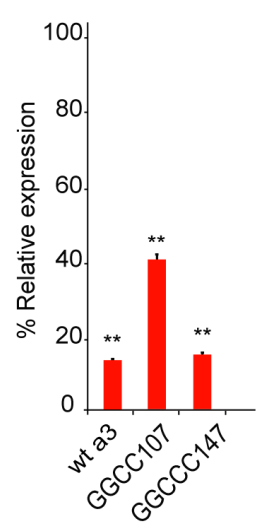

HEK293FT cell line

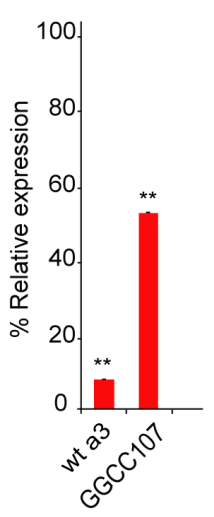


bioRxiv preprint doi: https://doi.org/10.1101/2021.01.19.427285; this version posted January 21, 2021. The copyright holder for this preprint (which was not certified by peer review) is the author/funder, who has granted bioRxiv a license to display the preprint in perpetuity. It is made available under aCC-BY 4.0 International license.

\section{Figure 8}
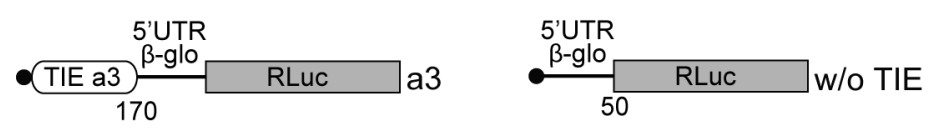

+ GMP-PNP



- TIE a3

- w/o TIE
+ cycloheximide

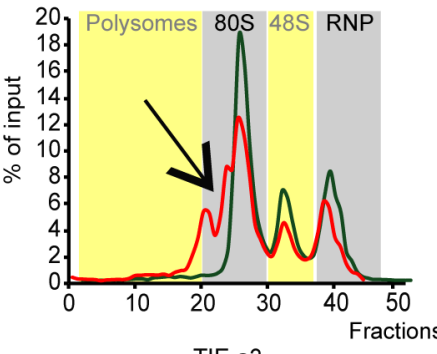

- TIE a3

- w/o TIE
+ Geneticin



- TIE a3

- w/o TIE 
bioRxiv preprint doi: https://doi.org/10.1101/2021.01.19.427285; this version posted January 21, 2021. The copyright holder for this preprint (which was not certified by peer review) is the author/funder, who has granted bioRxiv a license to display the preprint in perpetuity. It is made available under aCC-BY 4.0 International license.

\section{Figure 9}
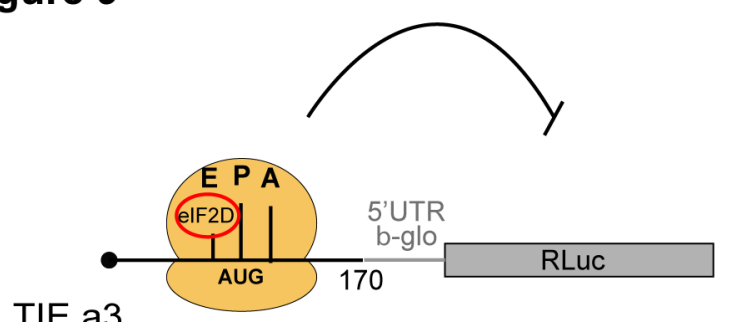

TIE a3

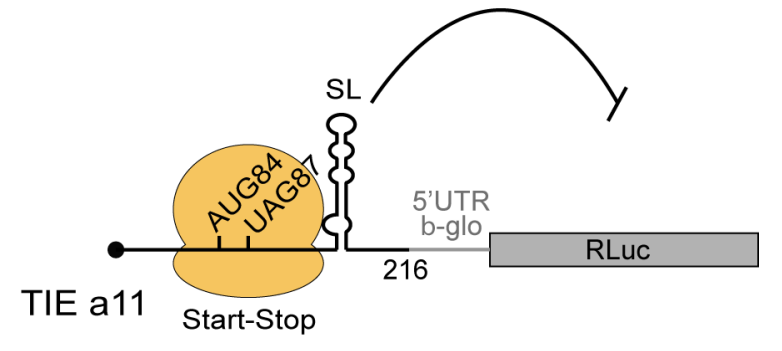




\section{Supplementary figure 1}

A
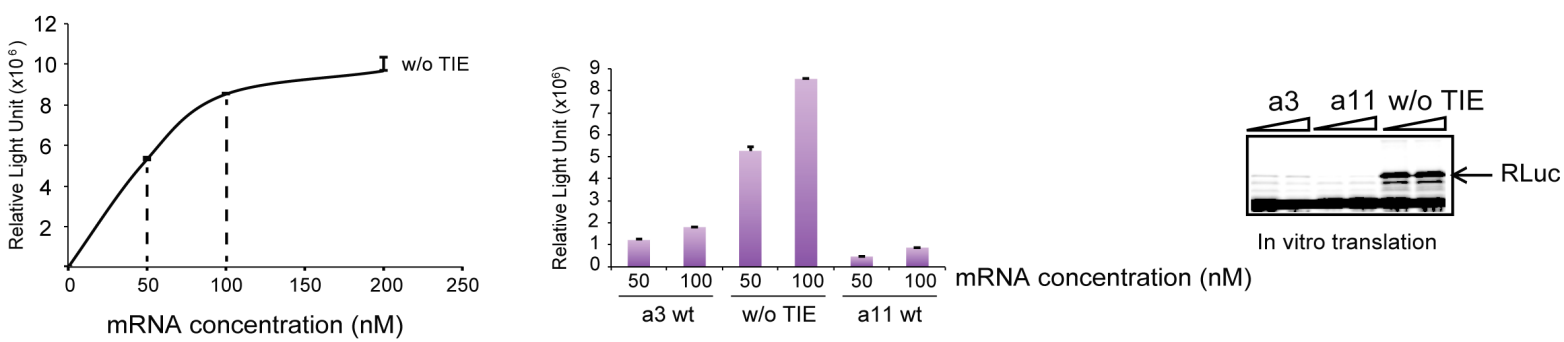

B

WGE

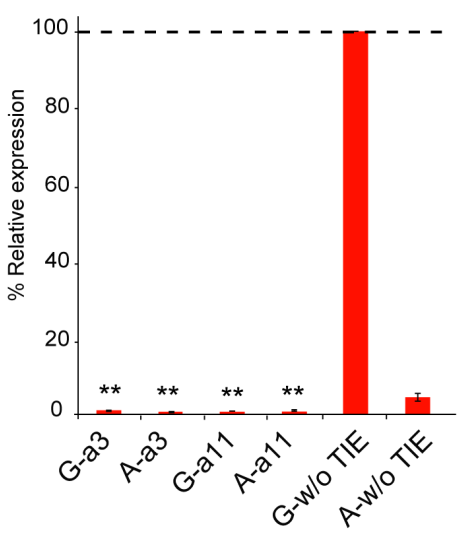

C

$50 \mathrm{nM}$

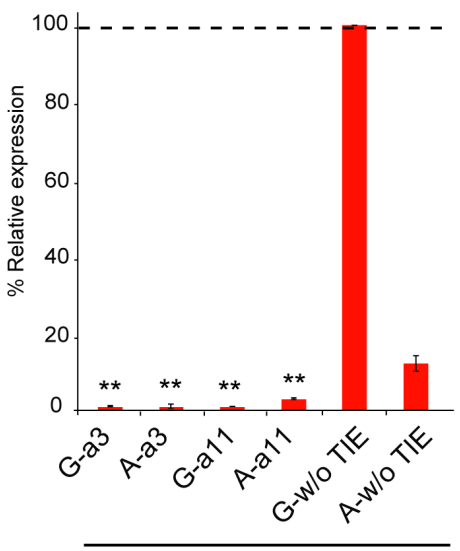

$50 \mathrm{nM}$
HeLa

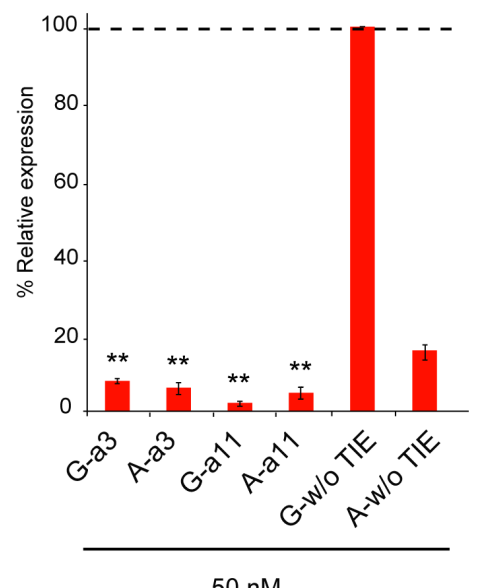

$50 \mathrm{nM}$

\section{HEK293FT cell line}

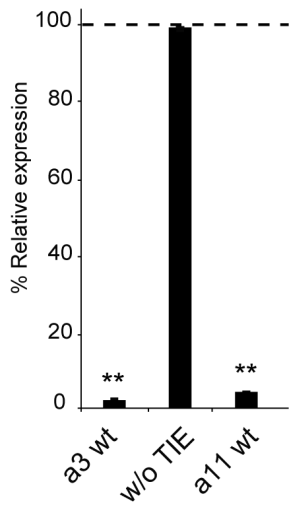

\section{C3H10T1/2 cell line}




D

TIE a3 5' deletions
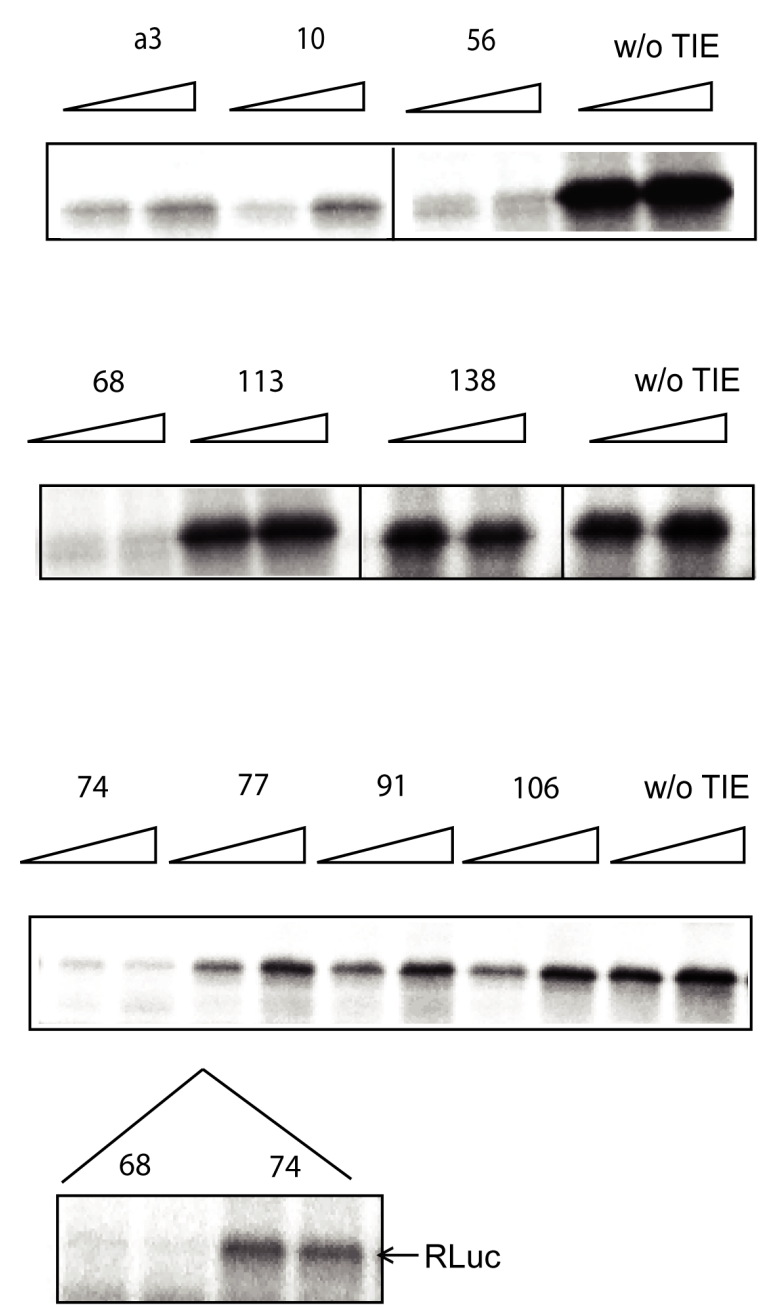

TIE a11 5' deletions

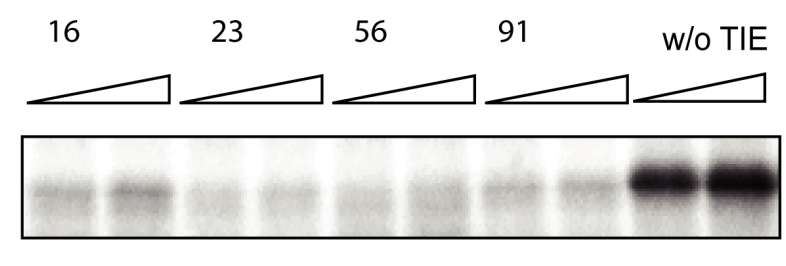

99

$110 \quad 139$

$188 \quad$ W/o TIE

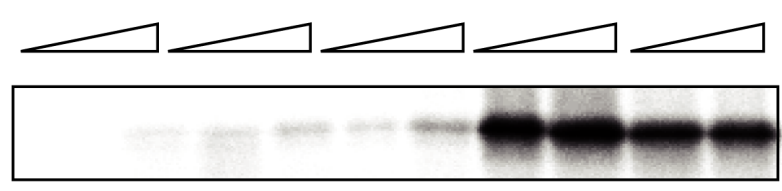

153

161

171

w/o TIE
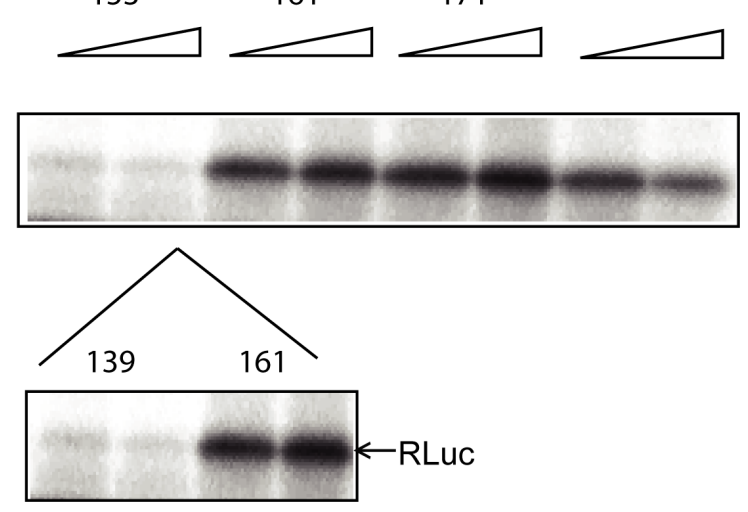
bioRxiv preprint doi: https://doi.org/10.1101/2021.01.19.427285; this version posted January $21,2021$. The copyright holder for this preprint (which was not certified by peer review) is the author/funder, who has granted bioRxiv a license to display the preprint in perpetuity. It is made available under aCC-BY 4.0 International license.

\section{Supplementary figure 2}

A

Probing by DMS on the TIE from a3

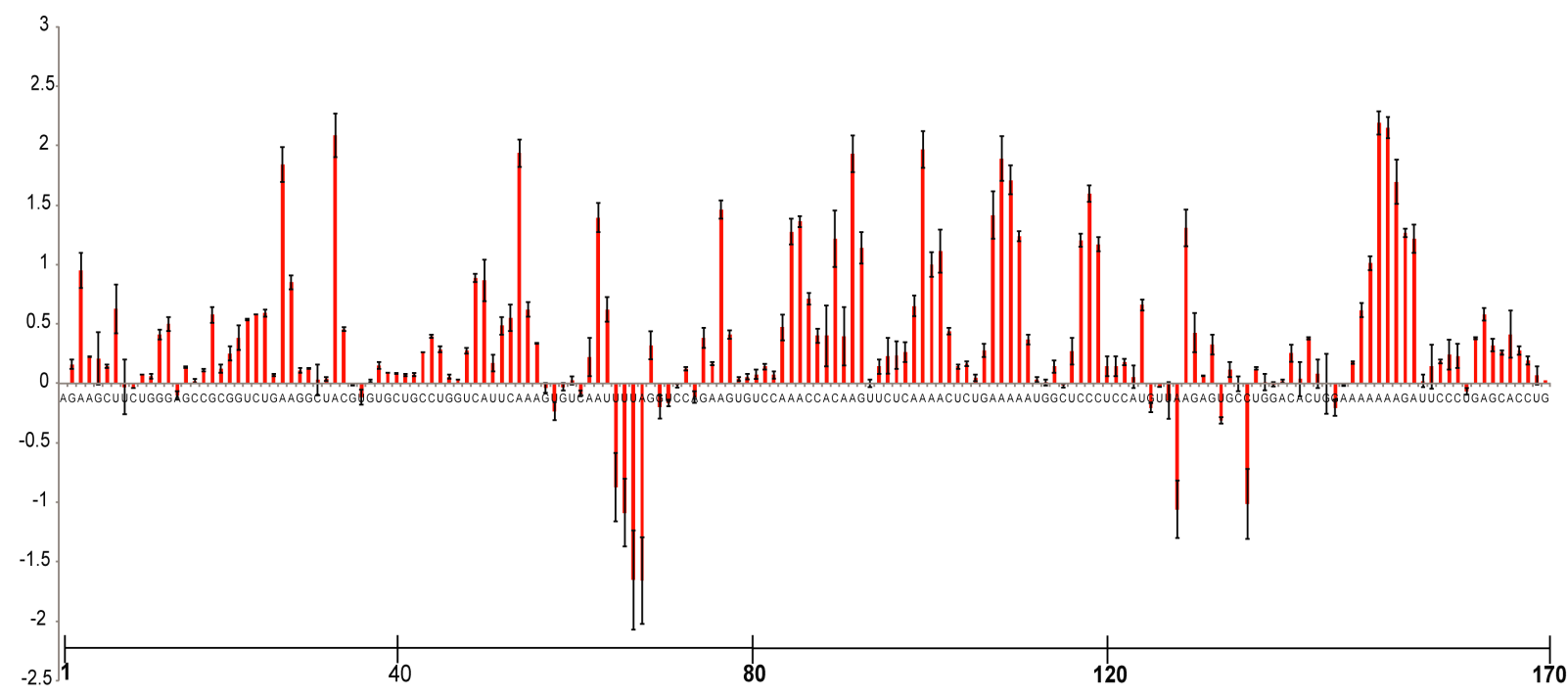

B

Probing by CMCT on the TIE from a3




bioRxiv preprint doi: https://doi.org/10.1101/2021.01.19.427285; this version posted January 21, 2021. The copyright holder for this preprint (which was not certified by peer review) is the author/funder, who has granted bioRxiv a license to display the preprint in perpetuity. It is made available under aCC-BY 4.0 International license.

C

Probing by DMS on the TIE from a11

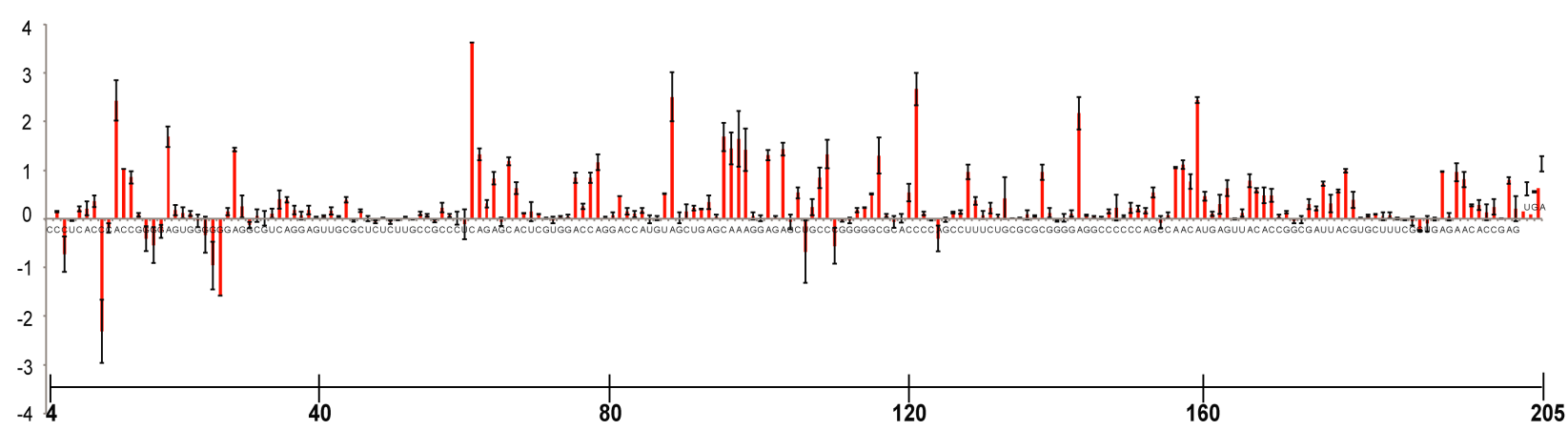

D

Probing by CMCT on the TIE from a11

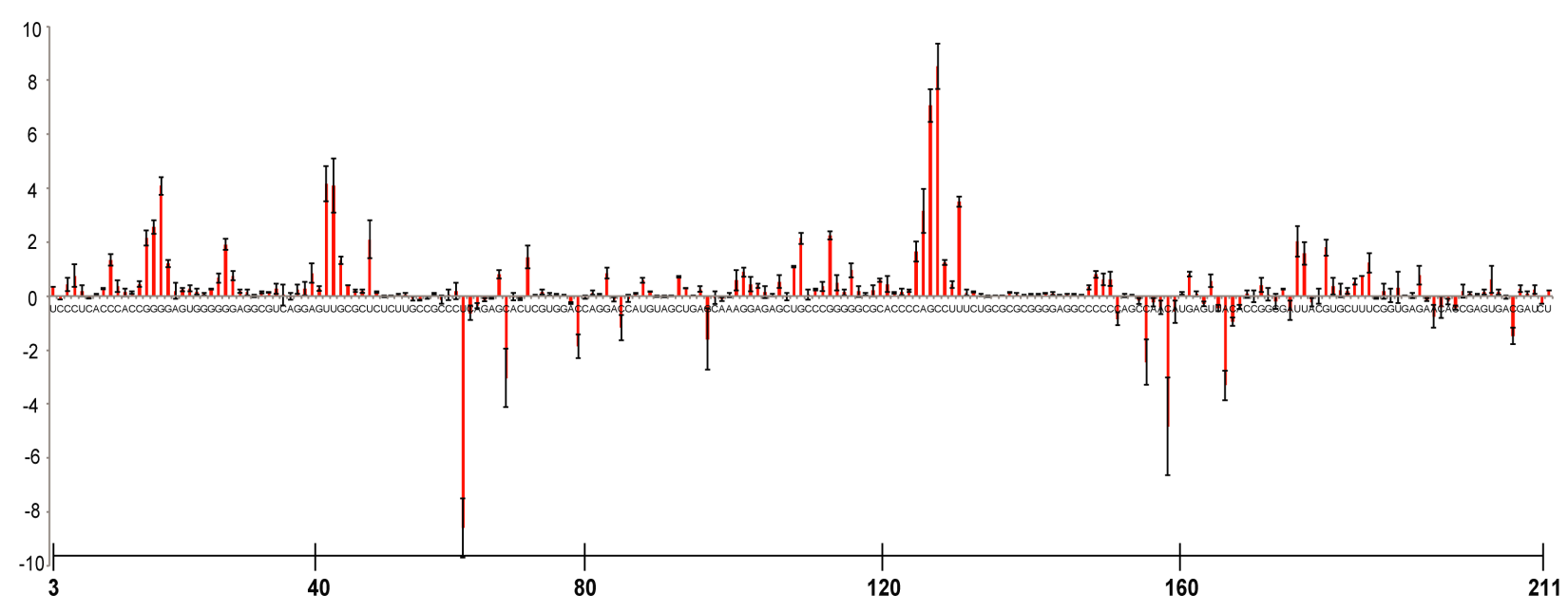


bioRxiv preprint doi: https://doi.org/10.1101/2021.01.19.427285; this version posted January $21,2021$. The copyright holder for this preprint (which was not certified by peer review) is the author/funder, who has granted bioRxiv a license to display the preprint in perpetuity. It is made available under aCC-BY 4.0 International license.

\section{Supplementary figure 3}

A

AUG111 mutations

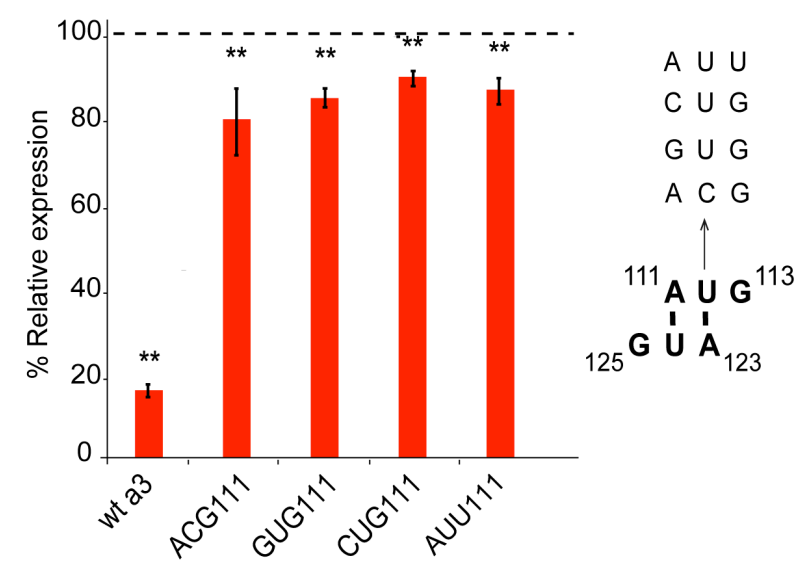

AUG111+AUG123 mutations

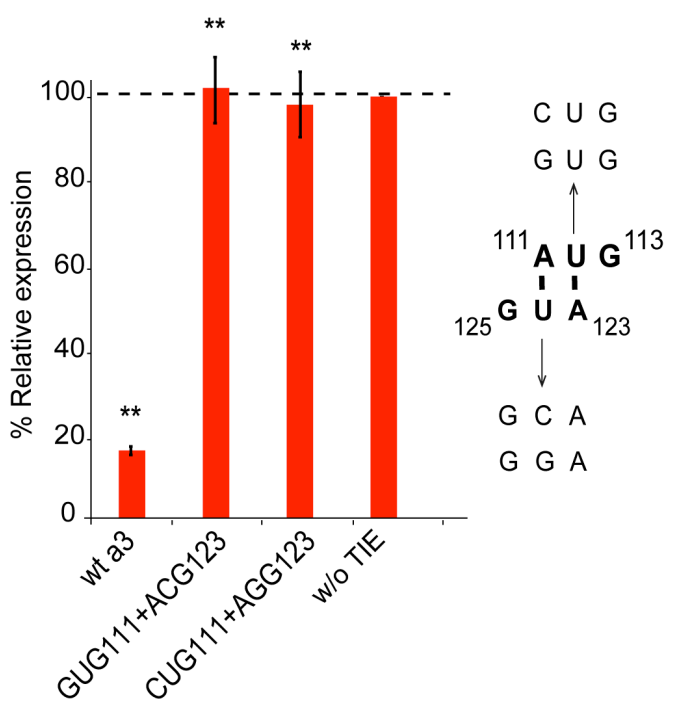

B

w/o inhibitor



- TIE a3

- a3 (AUG/UAC)111

+ GMP-PNP

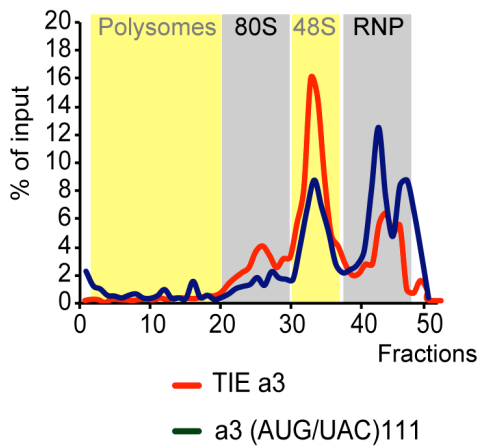




\section{Supplementary figure 4}

A
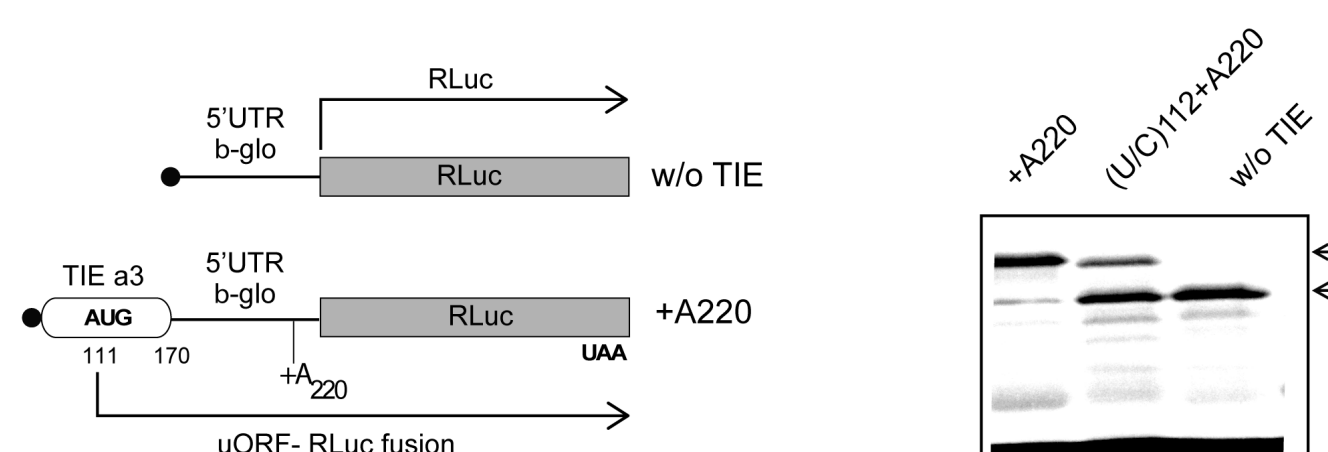

$+\mathrm{A} 220$
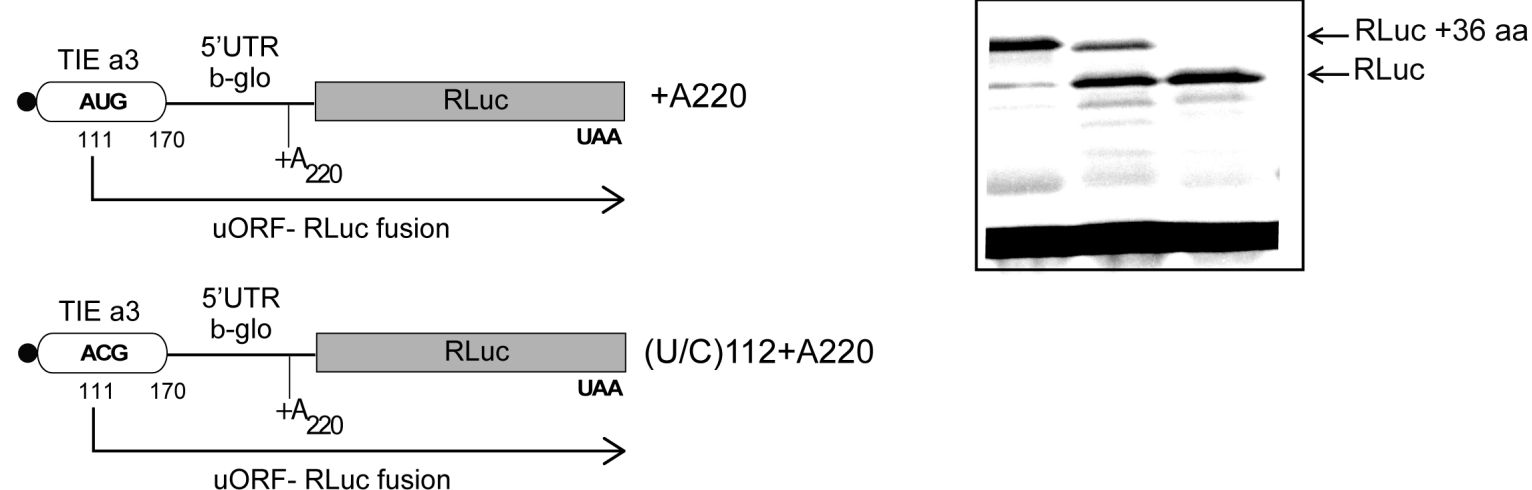

$(\mathrm{U} / \mathrm{C}) 112+\mathrm{A} 220$

B

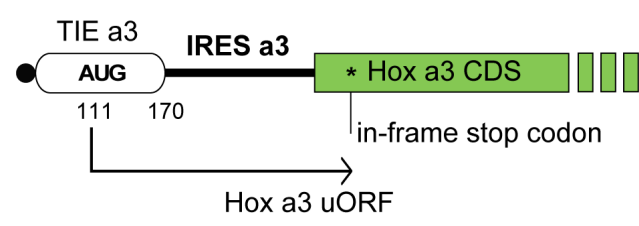

Hox a3 mRNA

Hox a3 uORF $\rightarrow$
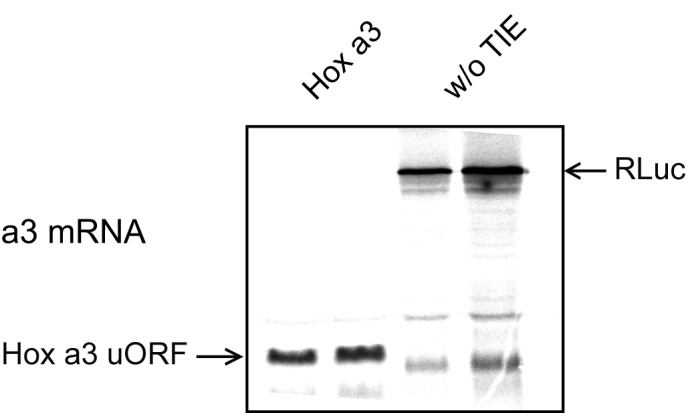
bioRxiv preprint doi: https://doi.org/10.1101/2021.01.19.427285; this version posted January 21, 2021. The copyright holder for this preprint (which was not certified by peer review) is the author/funder, who has granted bioRxiv a license to display the preprint in perpetuity. It is made available under aCC-BY 4.0 International license.

\section{Supplementary figure 5}
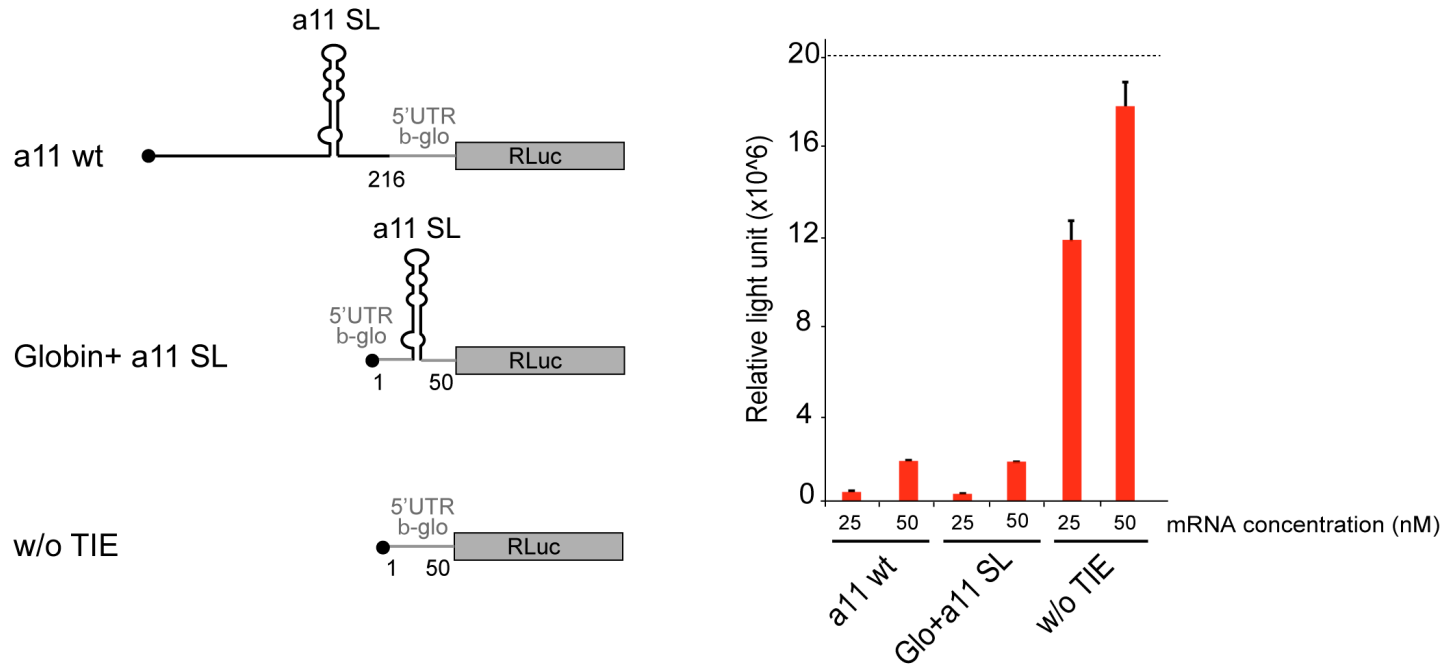
bioRxiv preprint doi: https://doi.org/10.1101/2021.01.19.427285; this version posted January 21, 2021. The copyright holder for this preprint (which was not certified by peer review) is the author/funder, who has granted bioRxiv a license to display the preprint in perpetuity. It is made available under aCC-BY 4.0 International license.

\section{Supplementary figure 6}

bioRxiv preprint doi: https://doi.org/10.1101/2021.01.19.427285; this version posted January 21,2021 . The copyright holder for this preprint (which was not certified by peer review) is the author/funder, who has granted bioRxiv a license to display the preprint in perpetuity. It is made available under aCC-BY 4.0 International license.

\section{Supplementary figure 7}

A

$\begin{array}{ll}\begin{array}{l}\text { Consensus } \\ \text { Conservation }\end{array} & \text { A A A C t CTCTG } \\ \text { F. catus } & \text { A A A C TCTCTG } \\ \text { M. musculus } & \text { A A A - - CTCTG } \\ \text { M. flaviventris } & \text { A A A - - CTCTG } \\ \text { H. sapiens } & \text { A A A TCTCTG } \\ \text { M mulatta } & \text { A A A - - CTCTG } \\ \text { P. anubis } & \text { A A A - - CTCTG } \\ \text { E. caballus } & \text { A A A T T TCTG } \\ \text { U. horribilis } & \text { A A A T T TCTG } \\ \text { C. dingo } & \text { A A ACTCTCTG }\end{array}$

A A A A A T G G C T

A A A A A T G G C T A A A A A TGG C T

A A A A A T G G T

A A A A A T GG T

A A A A A T G G T

A A A A T TGGT

A A A A A T G G C T

A A A A A T GGC T

A A A A A T GGC T

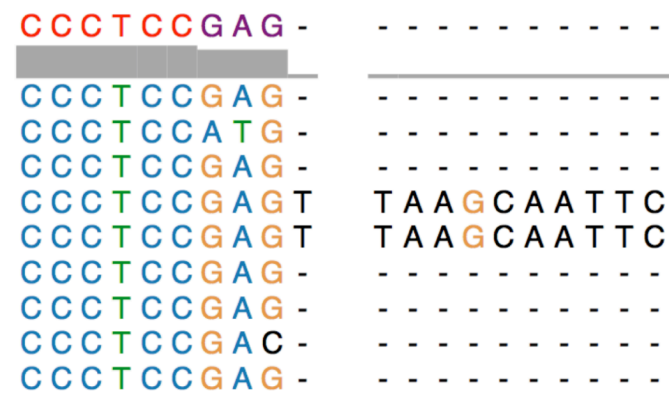

71

g c g c T c T c T c

A A T T T T T TTT

GCGCTCTCTC

GCGCTCTCTC

GCGCTCTCT T

GCGCTCTCT T

G A GC T C T C T C

G A G C T C T C T C

$\ldots . . . .$.

111

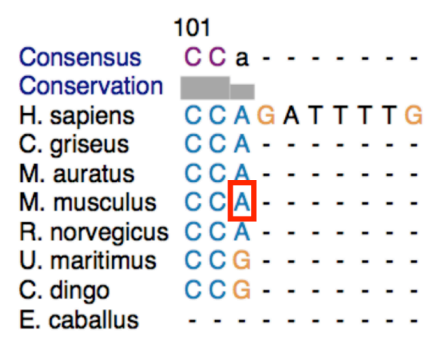

$\ldots . . .$.

$\ldots$ t G c a G c T

ACT T A A G A T

C AGTGAGGT T

A

$\ldots . . . .$.

$\ldots . . . \cdot$

$\ldots \ldots$

$\ldots \ldots$

$\ldots . .$.

- GGTAGC T

- - GGTAGCT

- . TG TAGC T

-. TGCAGCT

- . TGCAGC T

- . TGCAGC T

$\ldots . . .$.

$161 \quad 171$

171

81

a g g g a c T c g

91

$\ldots . .-\mathrm{CTCC}$

A GCGCATTCG

A G C GCATTCG

$A G A G C A C T C G$

$A G A G C G C T C G$

G G C GCACT T G

G GCGCACT T G

$\ldots . . .$.

131

GAGCA - a a g

GAGCA T G CGG

$G A G C A-A A G$

$G A G C A-A A G$

$G A G C A$ - . A A G

$G A G C A-A A G$

GAGCA - CAC

GAGCA - C A G

$\ldots . .$.

t Gg a C c a g g A

TG T T C T G A A A

T GGACCAGGA

$T G G A C C A G G A$

TGGA C CAGGA

TGGACCAGGA

A GGGCCAGGA

A GGGCCAGGA

$\ldots \ldots$

141

G a g A G c t GC t

GACAGTTGC -

$G A G A G C T G C T$

GAGAGCTGCT

G A G A G C T G C C

G A A A GCT GCT

GCGAGTGGCC

G C G A G C G C A

$\cdots \cdot \cdots$

181

CGCggGGAGG CCCCCC ...

C TGAAGA A ACTCCCGTTC CGCGGGGAGG CCCCCC...

CGCGGGGAGG $\mathrm{CCCCCC}$... CGCGGGGAG $\mathrm{CCCCCC}$. . . .

CCGCAGCCTT TCTG-... CG
$C C G C A G C C T T$

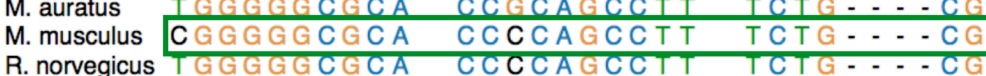

$\begin{array}{lll}\text { R. norvegicus } \\ \text { U. maritimus } T-G G G G C G C A & C C T C A G C C T C & C C C G \\ \end{array}$

AGCGGGGAGG CCCCCC...

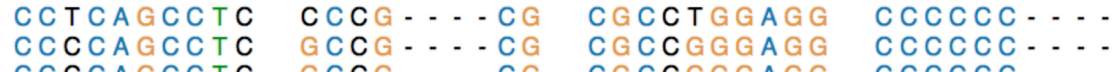

C. dingo T - GGGGCGCA CCCCAGCCTC

$G C C G \ldots . C G$

$\mathrm{CCCCCC}$ - . - - 